Article

\title{
Ground-Based Hyperspectral Image Analysis of the Lower Mississippian (Osagean) Reeds Spring Formation Rocks in Southwestern Missouri
}

\author{
Ünal Okyay ${ }^{1, *}$, Shuhab D. Khan ${ }^{1}$, M. R. Lakshmikantha ${ }^{2}$ and Sergio Sarmiento ${ }^{2}$ \\ 1 Department of Earth and Atmospheric Sciences, University of Houston, Houston, TX 77204, USA; \\ sdkhan@uh.edu \\ 2 Repsol USA, 2455 Technology Forest Blvd., The Woodlands, TX 77381, USA; \\ m.lakshmikantha@repsol.com (M.R.L.); sergio.sarmiento@repsol.com (S.S.) \\ * Correspondence: uokyay@uh.edu; Tel.: +1-832-375-5693
}

Academic Editors: Magaly Koch, Richard Gloaguen and Prasad S. Thenkabail

Received: 17 August 2016; Accepted: 6 December 2016; Published: 19 December 2016

\begin{abstract}
Ground-based hyperspectral imaging is fairly new for studying near-vertical rock exposures where airborne or satellite-based imaging fail to provide useful information. In this study, ground-based hyperspectral image analysis was performed on a roadcut, where diagenetic tripolite facies is observed in southwestern Missouri. Laboratory-based reflectance spectroscopy and hyperspectral image analyses were also performed on collected samples. Image classification was performed using Spectral Feature Fitting (SFF) and Mixture-tuned Match Filtering (MTMF) with laboratory- and image-derived end-member spectra. SFF provided thorough yet detailed classification, whereas MTMF provided information on the relative abundances of the lithologies. Ground-based hyperspectral imaging demonstrated its potential to aid geological studies providing valuable information on mineralogical and lithological variations rapidly and with two-dimensional continuity in inaccessible rock faces of near-vertical outcrops. The results showed decreasing tripolite abundance going downward in the investigated vertical succession. Also, a leaching pattern has been observed such that persistent and continuous limestone layers become lenses and patches towards the upper portion of the outcrop. These observations show that the effect of tripolitization decreases when going deeper in the succession, suggesting that the fluid responsible for the weathering of siliceous precursors may have been flowing from top to bottom and thus have had a meteoric origin.
\end{abstract}

Keywords: ground-based hyperspectral imaging; laboratory-based hyperspectral imaging; reflectance spectroscopy; Pineville tripolite; tripolitization; diagenetic facies; rock alteration

\section{Introduction}

Complementing the conventional field studies, virtual outcrop models created using ground-based light detection and ranging (LiDAR) combined with high-resolution digital photography (i.e., from scanner-mounted cameras or GigaPan panoramas) have provided a framework for geological studies such as geo-structural analysis [1,2] or stratigraphic modeling, and reservoir analogues [3-7] in near vertical outcrops. The analysis and interpretations for the latter using point clouds and virtual models, however, have been manual, which requires user interaction and experience so as to pick out or track geological features. In addition, these models do not provide complete information about lithological and mineralogical variations. Mineralogical changes diagenetic in nature are particularly important for evaluating sedimentary reservoirs for alteration minerals, groundwater, and hydrocarbons they host in the subsurface [8,9]. Imaging spectroscopy, or hyperspectral imaging, and well-established spectral processing methods (see [10] for details), on the other hand, provide a means of identifying mineral types and mineralogical changes. Most minerals show diagnostic absorption features caused 
by vibrational or electronic processes in the mineral lattice, which manifest themselves in shortwave infrared and visible near infrared, respectively [11,12].

Until recently, most hyperspectral data used in geology have been acquired either from spaceborne and airborne sensors $[9,13]$ or from laboratory-based sensors dedicated for drill-core scanning [14-16]. Owing to recent advances in sensor technology, there has been an increasing interest in hyperspectral data collected using ground-based platforms for geological applications [17-22]. Ground-based hyperspectral data are particularly important and useful for near-vertical cliffs, roadcuts, and quarry walls where airborne or spaceborne data fail to provide an adequate viewing angle or resolution for detailed analysis. In addition, the steep and high rock faces of such outcrops are often inaccessible, so conventional field methods cannot be applied. These outcrops provide excellent vertical rock exposures for observations of lithostratigraphy, depositional history and architecture, mineralogy, and geological heterogeneities. Additionally, spatial variations in lithology and mineralogy of an outcrop are of particular importance for geological studies such as reservoir analogues.

Ground-based sensors offer high flexibility and mobility for data acquisition, which allows more control on the scanning geometry for the optimal scanning conditions. This could also help with focusing only on outcrop faces and avoiding non-outcrop materials (such as vegetation, debris, and, in the case of some roadcuts, draped meshes or metallic nets) through a careful planning of the scanning campaign (where possible). Along with the many benefits ground-based hyperspectral sensors have to offer, there are certain limitations. These sensors could acquire sizeable (multi-gigabyte) data in only a few minutes due to very high spatial and spectral resolution. The size of the data becomes problematic during (i) image acquisition, which could result in dropped image frames; and (ii) image processing in the absence of adequate computer hardware. The cylindrical image geometry of the ground-based hyperspectral images may result in apparent geometric distortion towards the edges of the images, particularly in very close-range applications. The sensors operate optimally in a non-condensing environment within their operating temperature ranges. Thus, the use of these sensors could be limited by environmental conditions. Ground-based hyperspectral systems provide high-resolution data from vertical rock faces in the expense of wider areal extent. That is, in fact, the primary reason that ground-based systems are used for studies at the outcrop scale rather than the regional scale. Depending on the location and condition of the outcrop, not all near-vertical rock faces are suitable for ground-based hyperspectral data collection due to safety issues (i.e., heavy traffic, rockfall hazard, etc.). Thus, careful planning for the scanning campaign and data collection is necessary.

Apart from their field applications, the sensors used in ground-based platforms can also be used in laboratory settings for advanced imaging spectroscopy analysis of samples, rock chips, and drill cores $[23,24]$. Laboratory-based imaging spectroscopy provides accurate spectral information comparable to reflectance spectroscopy from the surface of the samples with a very high spatial resolution and lateral continuity. Thus, it not only allows identification of minerals and mixtures but also evaluation of the spatial distribution and variability of these minerals in the surface of analyzed samples. Therefore, an integrated approach bringing multiscale observations extracted from reflectance spectroscopy, laboratory-based hyperspectral, and ground-based hyperspectral data together could provide more comprehensive evaluation of the outcrops for geological studies.

The Mississippian carbonate rocks, often called Mississippian Lime, comprise a large portion in the subsurface of northern Oklahoma and southern Kansas. These rocks include prolific petroleum reservoirs that have been drilled vertically since the 1940s and horizontally since the late 2000s. The recent increase in horizontal drilling has also increased interest in the lithostratigraphy, facies architecture, and depositional history of these rocks in the subsurface [25]. Although these subsurface rocks have been studied by several researchers [26-29], a regionally consistent and comprehensive lithostratigraphic architecture of the Lower Mississippian succession and the petroleum reservoirs it hosts is yet to be constructed [30]. In order to gain a better understanding of petroleum reservoirs, outcrop analogues have been used in reservoir studies incorporating information on lithostratigraphy, biostratigraphy, depositional and diagenetic history, and geological heterogeneities [30]. As direct 
analogues, correlative Lower Mississippian rocks exposed in natural outcrops and near vertical roadcuts in the quad state area of southeast Kansas, southwest Missouri, northeast Oklahoma, and northwest Arkansas serve as an invaluable reference for subsurface rocks. Some of the rock exposures in this area host tripolite facies similar to the reservoir facies that have been exploited in southcentral Kansas and northern Oklahoma [31]. Although tripolite is known to be a diagenetic alteration product of precursor siliceous rocks, proposed explanations for diagenesis and formation of tripolite in this area have been controversial.

This study used high-resolution, ground-based hyperspectral image analysis as a means of identifying lithological units and mapping their spatial distributions in the Lower Mississippian (Upper Kinderhookian to Osagean) exposures, particularly of the Reeds Spring Formation in southwest Missouri, as a semi-quantitative method complementary to conventional geological field studies. This study also aims to provide new observations and insight for explaining tripolite formation in the study area. The main contribution of this study, therefore, is twofold: (i) assessment of ground-based hyperspectral data for high-resolution lithostratigraphic analysis similar to vertical stratigraphic sections except with 2D continuity; and (ii) bringing observations together from reflectance and multiscale imaging spectroscopy data that have not been available previously for better understanding of the presence and formation of tripolite in the investigated outcrop. Given that the exposures of the Pineville tripolite facies near the top of the Reeds Spring Formation are not present throughout the Mississippian outcrop belt but observed locally in the tristate area of southwest Missouri, northwest Arkansas, and northeast Oklahoma [25], the diagenesis process responsible for tripolite formation should not change drastically between exposures.

Although well-established spectral libraries such as USGS or ASTER have broad information about spectral properties of rocks and minerals, particular information concerning the lithological units of Lower Mississippian is not available. Consequently, laboratory reflectance analysis has also been incorporated so as to evaluate the spectral properties of the lithological units present in the Lower Mississippian exposures and to build a spectral library for these units. As the focus of this paper is not algorithm and/or method development, well-known image processing algorithms such as Empirical Line Calibration, Spectral Feature Fitting, and Mixture-tuned Match Filtering have been adopted.

\subsection{Geological Setting}

The Mississippian subsystem is one of two subsystems of the Carboniferous System along with the Pennsylvanian subsystem. Although the global stage names for the Mississippian subsystem were accepted (Tournaisian, Viséan, and Serpukhovian, in ascending order) by the Subcommission on Carboniferous Stratigraphy (SCCS) of International Commission on Stratigraphy (ICS) in 2003, a regional stage nomenclature (Kinderhookian, Osagean, Meramecian, and Chesterian, in ascending order) has been used for North America; for more detail see [32,33]. Thus, in this paper, the North American regional stage nomenclature has been followed.

The depositional history in the mid-continent shows characteristics of transgressive-regressive inland sea deposition along a relatively stable, cratonic margin during the Mississippian. The carbonates were deposited across a broad, shallow-water carbonate platform known as the Burlington Shelf [26,34], resulting in Lower Mississippian carbonates extending across the mid-continent from Illinois to Arizona [35] (Figure 1). Eventual progradation and aggradation of the Burlington Shelf allowed deposition of thick and extensive Lower Mississippian successions in the region. The Lower Mississippian rocks from Upper Kinderhookian to Chesterian are exposed in natural outcrops in the quad state area due to subsequent sporadic uplifting during the Late Paleozoic. Majority of these exposures are located in northeast Oklahoma, northwest Arkansas, and southwest Missouri with limited exposure in southeast Kansas (Figure 2).

The lithostratigraphy of the Lower Mississippian rocks in this region has been described and several revisions have been suggested. Currently recognized lithostratigraphic units and nomenclature, however, vary in the quad state area. In this paper, the nomenclatural revisions suggested by [25] 
have been adopted. They suggested use of Boone as a group rather than a formation or member. The Boone Group (formerly regarded as the Boone Formation) includes the Osagean Reeds Springs Formation, the Bentonville Formation, the Short Creek Member, and the Meramecian Ritchey Limestone (in ascending order) (Figure 3). As it is one of the major hydrocarbon bearing formations in the Mississippian Lime play that has been exploited in north-central Oklahoma [31], the focus of this paper is particularly on the Reeds Spring Formation and Pineville tripolite facies it hosts.

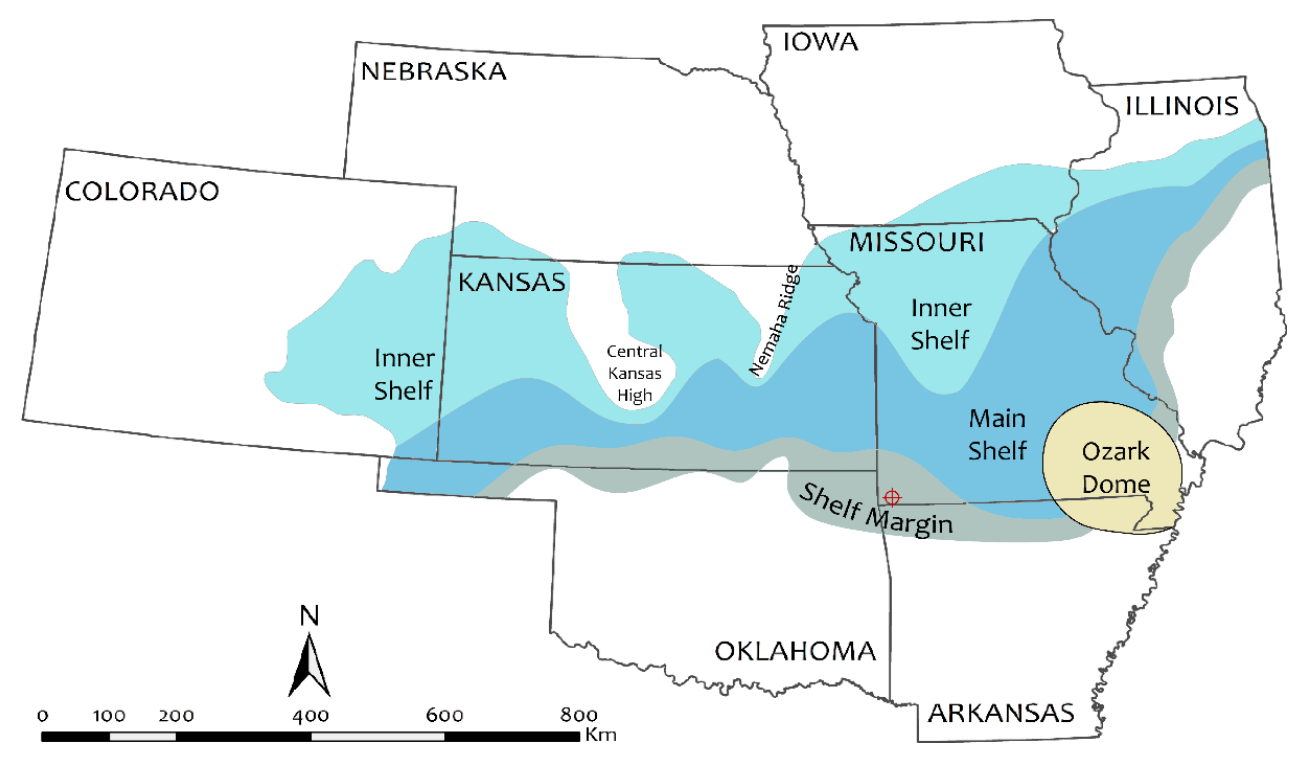

Figure 1. Paleogeography and lithofacies distribution of the Lower Mississippian. The area studied in this study, which falls within the Shelf Margin, is depicted by the crosshair in southwest Missouri. (modified after [36]).

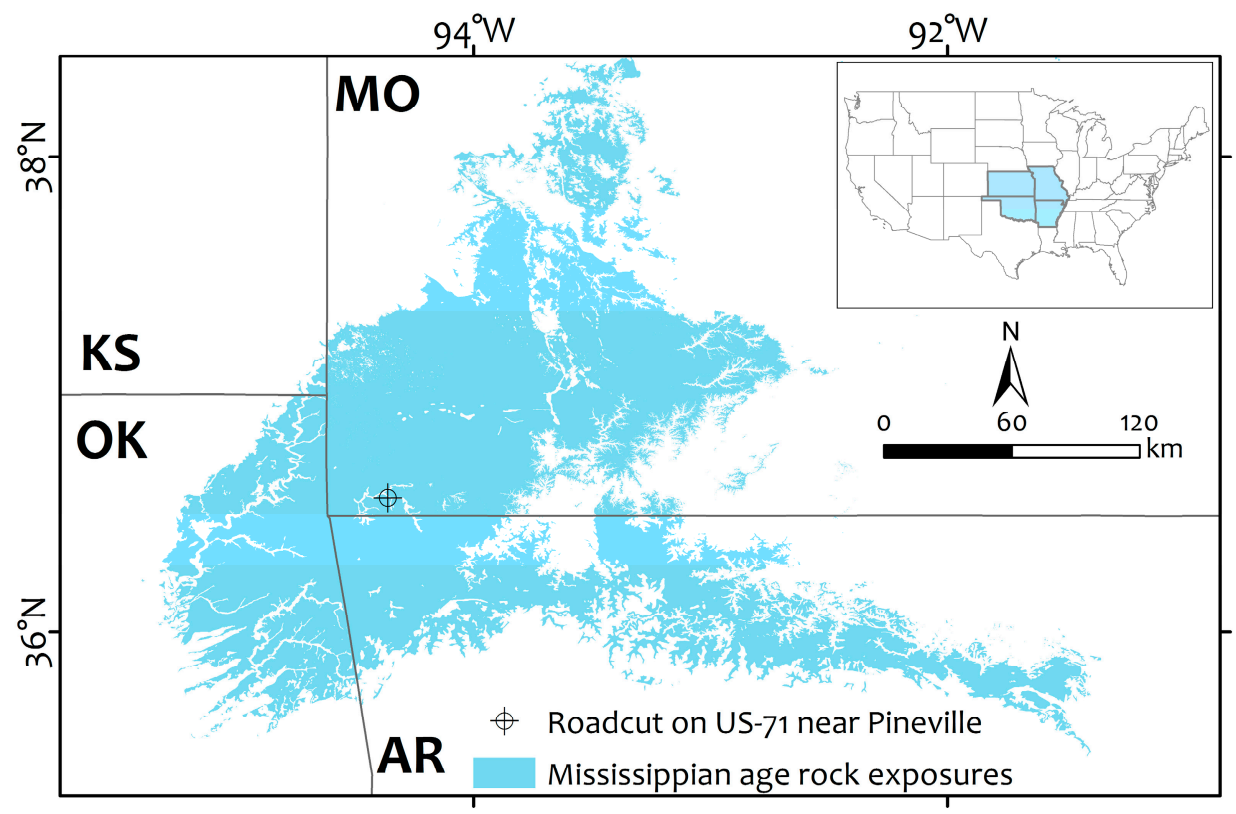

Figure 2. Mississippian rock exposures in the quad state area of southeast Kansas (KS), southwest Missouri (MO), northeast Oklahoma (OK), and northwest Arkansas (AR). The crosshair depicts the location of the roadcut on US-71 Hwy near Pineville, Missouri studied in this paper. 


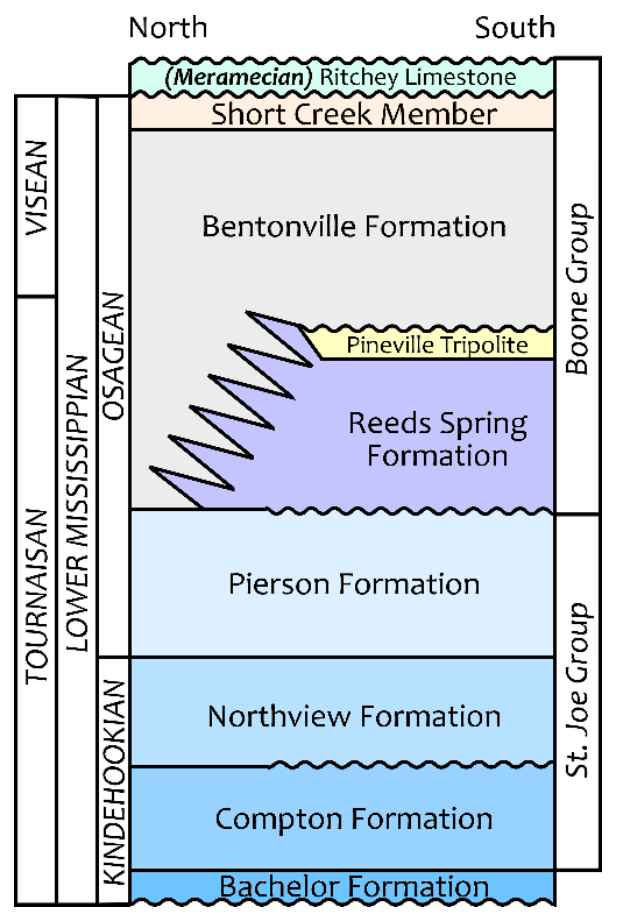

Figure 3. Generalized lithostratigraphy of Lower Mississippian subsystem in southwest Missouri, northwest Arkansas, and northeast Oklahoma, incorporating nomenclatural revisions suggested in Mazzullo et al. [25] (modified after [25,37]).

The Boone Group rocks exposed in the tristate area of southwest Missouri, northwest Arkansas, and northeast Oklahoma were deposited during Early Osagean to Chesterian time within the shelf margin [34]. The Boone Group rocks are characterized by medium to coarse crystalline and cherty fine to medium crystalline crinoidal limestone [36]. The Reeds Spring Formation, the basal unit of the Boone Group, consists mainly of fine grained dark gray (Munsell color [38]: GLEY1 4/N) cherty limestone. The dark bluish-gray (Munsell color: GLEY2 10B 6/1) chert comprises a variable yet large percentage of the formation, usually reaching up to $60 \%-70 \%$ [36]; at some localities it can be as much as $100 \%$ of the section [31]. The mineralogy commonly associated with the rocks of Reeds Spring Formation is typical for their lithologies, i.e., carbonate minerals for limestone and fine-grained silica for chert. The monotonous lithology dominated by gray limestone and chert in the Reeds Spring Formation grades into pale yellow (Munsell color: 2.5Y 8/4) tripolite near the unconformable top of the Reeds Spring Formation [31,36,39]. These tripolite-dominated rocks have been formally recognized as the Elsey Formation in Southwestern Missouri but have not been formally recognized at all in Northern Arkansas and Northeastern Oklahoma [36]. Mazzullo et al. [25,31] suggested the abandonment of the Elsey Formation as a formal unit and recognition of the Pineville tripolite facies for the sake of consistency in the tristate area. The exposures of the Pineville tripolite facies near the top of the Reeds Spring Formation can be seen locally along new roadcuts of U.S. Hwy 71 in southwest Missouri. Details on lithostratigraphic nomenclature and its revisions can be found in $[25,30,31]$.

\subsection{Overview of Tripolite}

Chert in the Reeds Spring Formation, or more generally in the Boone Group, can be observed in three types as penecontemporaneous chert (chert for short), later diagenetic chert, and tripolite. Discrete types of chert are identified and constrained in individual intervals in the vertical section of the Mississippian succession. Tripolite, for instance, near the top of the Reeds Spring Formation, is unconformably overlain by the Bentonville Formation (Figure 3). The term tripolite is used in reference to highly weathered light-colored low-density siliceous rocks of any age characterized by 
high microporosity and permeability [37,40]. Tripolite is regarded as a diagenetic weathering product of calcareous chert or siliceous limestone from which carbonates have been leached out by meteoric fluids [40]. Although the occurrence of tripolite has been associated with in situ weathering and leaching in Missouri and Oklahoma [37,41], it is controversial whether the precursor rock was siliceous limestone or calcareous chert [41]. Tripolite may include remnants of unaltered limestone or chert [37], which can be observed as unsilicified lenses of limestone scattered throughout the tripolite facies in southwestern Missouri [39].

\section{Materials and Methods}

\subsection{Study Area}

Along U.S. Hwy 71, a series of vertical roadcuts can be seen on both sides of the highway providing continuous and greater composite thickness of the Lower Mississippian succession in southwest Missouri owing to the topographic relief. The roadcut studied in this paper is located on the northbound side of U.S. Hwy 71 to the south of Pineville, Missouri, approximately eight miles $(13 \mathrm{~km})$ from the Missouri-Arkansas state boundary (Figure 4A). This roadcut hosting rocks of Reeds Spring Formation (of the Boone Group) is approximately $130 \mathrm{~m}$ long and provides approximately $14 \mathrm{~m}$ composite thickness of the vertical succession. This portion of the highway was constructed in 2006; therefore, the roadcut provides a relatively fresh vertical rock face compared to natural outcrops elsewhere in the area except sporadic surface stains with limited lateral extents, which could be attributed to percolating rain water. Hyperspectral images of the outcrop were collected only from the southerly wall as it provides better illumination conditions, resulting in less shadow due to surface relief (Figure 4B). Along with hyperspectral data, representative samples of lithological units (54 in total: 18 tripolite, 20 chert, and 16 limestone samples) were collected from the accessible parts of the outcrop for the purpose of ground-truthing and comparison. In order to assess the spatial variability, samples were collected from different locations and levels along the roadcut where accessible. Owing to the road gradient, some portions not accessible to the east become accessible to the west of the roadcut, which allowed accessibility to stratigraphically higher levels. Most of the samples were collected from within seemingly homogenous units in terms of color and texture as discrete end-members, along with some collected from the lithological contacts. The sampling locations are given in Figure 5.
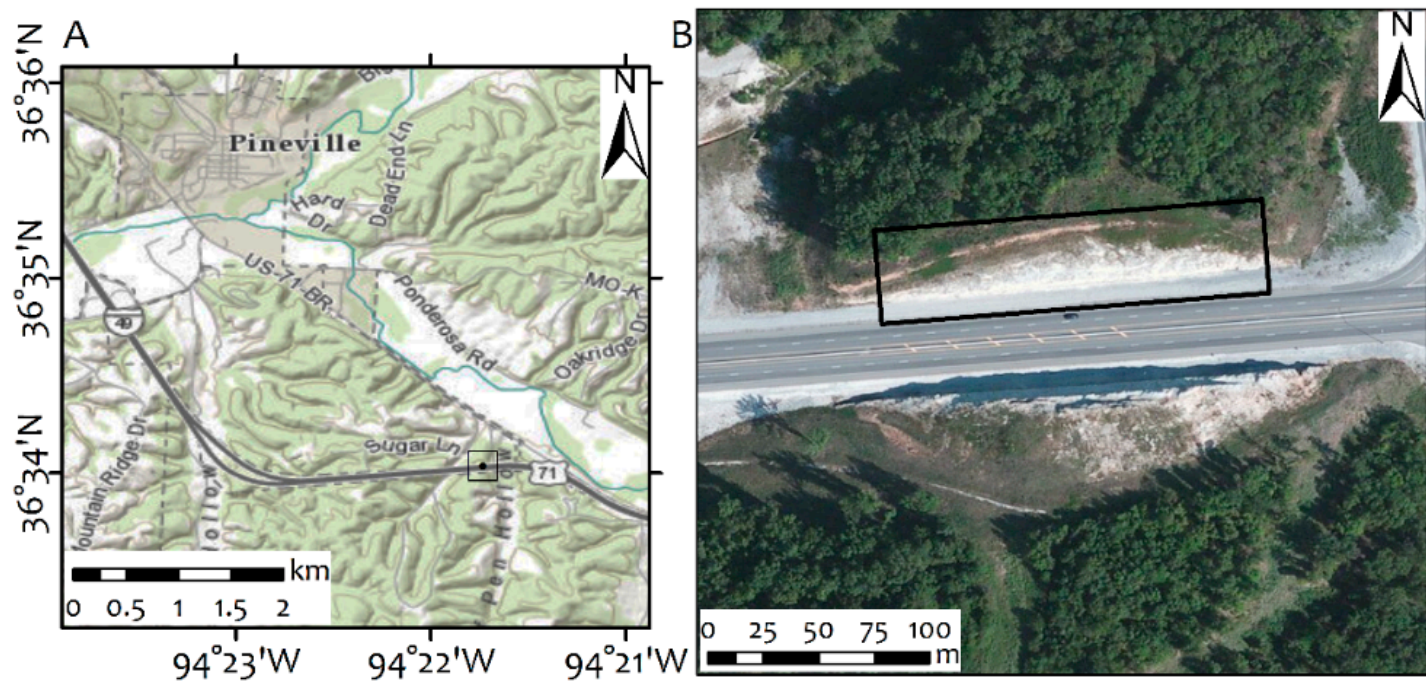

Figure 4. (A) Location of the roadcut on US-71 Hwy near Pineville hosting Reeds Spring Formation; (B) high-resolution satellite imagery of the studied roadcut. The solid black line depicts the scanned outcrop face of the roadcut. Both topographic map and high-resolution satellite imagery are courtesy of ESRI ArcGIS online. 


\subsection{Instrumentation and Data Collection}

The field-deployable hyperspectral imaging system includes two hyperspectral cameras from Spectral Imaging Ltd. (Specim), Finland (details are tabulated in Table 1). The first camera operates in the visible-near infrared (VNIR) part of the electromagnetic spectrum (EMS). The second camera, on the other hand, operates in the shortwave infrared (SWIR) part of the EMS. For this work, however, the emphasis is only on the shortwave infrared data as the main constituents in the outcrop have distinctive absorption features within the SWIR range. The SWIR camera collects data in 256 spectral bands over wavelengths from $900 \mathrm{~nm}$ to $2500 \mathrm{~nm}$, with approximately $6.3 \mathrm{~nm}$ bandwidth (full width at half maximum). The cameras work as a push-broom line scanner with 320 spatial pixels per line (across-track).

Table 1. Specifications of the VNIR and SWIR cameras from Spectral Imaging Ltd (Specim), Finland.

\begin{tabular}{lll}
\hline & \multicolumn{1}{c}{ VNIR Camera } & \multicolumn{1}{c}{ SWIR Camera } \\
\hline Spectrograph & ImSpector V10E & ImSpector N25E \\
Spectral range & $400-1000 \mathrm{~nm}$ & $900-2500 \mathrm{~nm}$ \\
Spectral Sampling & $0.72-5.8 \mathrm{~nm}^{1}$ & $6.3 \mathrm{~nm}$ \\
Sensor & $\mathrm{HgCdTe}(\mathrm{MCT})$ & Charged-couple device(CCD) \\
Spatial dimension & 1600 pixels $^{2}$ & 320 pixels \\
Spectral dimension & 840 pixels $^{1}$ & 256 pixels \\
Pixel pitch & $7.4 \mu \mathrm{m}$ & $30 \mu \mathrm{m}$ \\
Digitization & 12 -bit & 14-bit \\
\hline \multicolumn{2}{c}{${ }^{1}$ Adjustableby spectral binning; ${ }^{2}$ Adjustable by spatial binning. }
\end{tabular}

Ground-based hyperspectral data were acquired with the SWIR camera mounted on a rotating stage and tripod. In this setting, the outcrop image is created by rotating the stage at a constant angular velocity along-track. The fore-lens used for this study provides $24^{\circ}$ field-of-view (FOV), which results in an image with at-nadir pixel size of approximately $13.3 \mathrm{~mm}$ at $10 \mathrm{~m}$ distance. The outcrop data were acquired under clear-sky conditions on 3 May between 10:30 am and 12:30 pm. Laboratory-based hyperspectral (imaging reflectance spectroscopy) data of cleaned, otherwise unprepared samples were acquired on a custom-made scanning stage. In this setting, the image is created by moving the sample tray at a constant velocity along-track. As the scanning distance is much smaller in this setting, the same fore-lens of the SWIR camera provided much higher spatial resolution, resulting in an approximately $0.4 \mathrm{~mm}$ image pixel size at $0.35 \mathrm{~m}$ distance. The samples were illuminated by four $50 \mathrm{~W}$ quartz-halogen light bulbs, providing a full range of artificial light.

During outcrop data collection, a white reference panel made from polytetrafluoroethylene (PTFE) similar to Spectralon ${ }^{\circledR}$ and two $(\sim 3 \%$ dark and $\sim 20$ gray toned $)$ custom-made calibration panels $[42,43]$ with known reflectance (Figure 6) were placed parallel to the outcrop surface within the sensor's FOV. Similarly, during laboratory data collection a Labsphere Spectralon ${ }^{\circledR}$ standard and calibration panels with known reflectance were scanned along with the samples. Prior to hyperspectral data collection (both in the field and in the laboratory), initial scans were performed so as to determine the best exposure (integration time). The exposure was adjusted so that the pixels with highest albedo, usually from the white reference panel, are slightly lower than saturation. Following the final data collection, a dark image was acquired with the same exposure for radiometric calibration purposes.

A FieldSpec Pro spectroradiometer from Analytical Spectral Devices, Inc. (ASD) was used for laboratory (non-imaging) reflectance spectroscopy. The spectroradiometer operates in full-range collecting data in 2151 channels over wavelengths from $350 \mathrm{~nm}$ to $2500 \mathrm{~nm}$ with $1.4 \mathrm{~nm}$ and $2 \mathrm{~nm}$ bandwidths, in VNIR and SWIR, respectively. The spectroscopy data were collected using a bare fiber optic cable with $25^{\circ}$ FOV attached to a contact probe with a broadband direct-current light. The spectroradiometer was optimized and calibrated using a Labsphere Spectralon ${ }^{\circledR}$ diffuse reflectance 
standard and dark current. Each spectrum was the average of five replicate spectra collected from an area of $3.6 \mathrm{~cm}^{2}$.

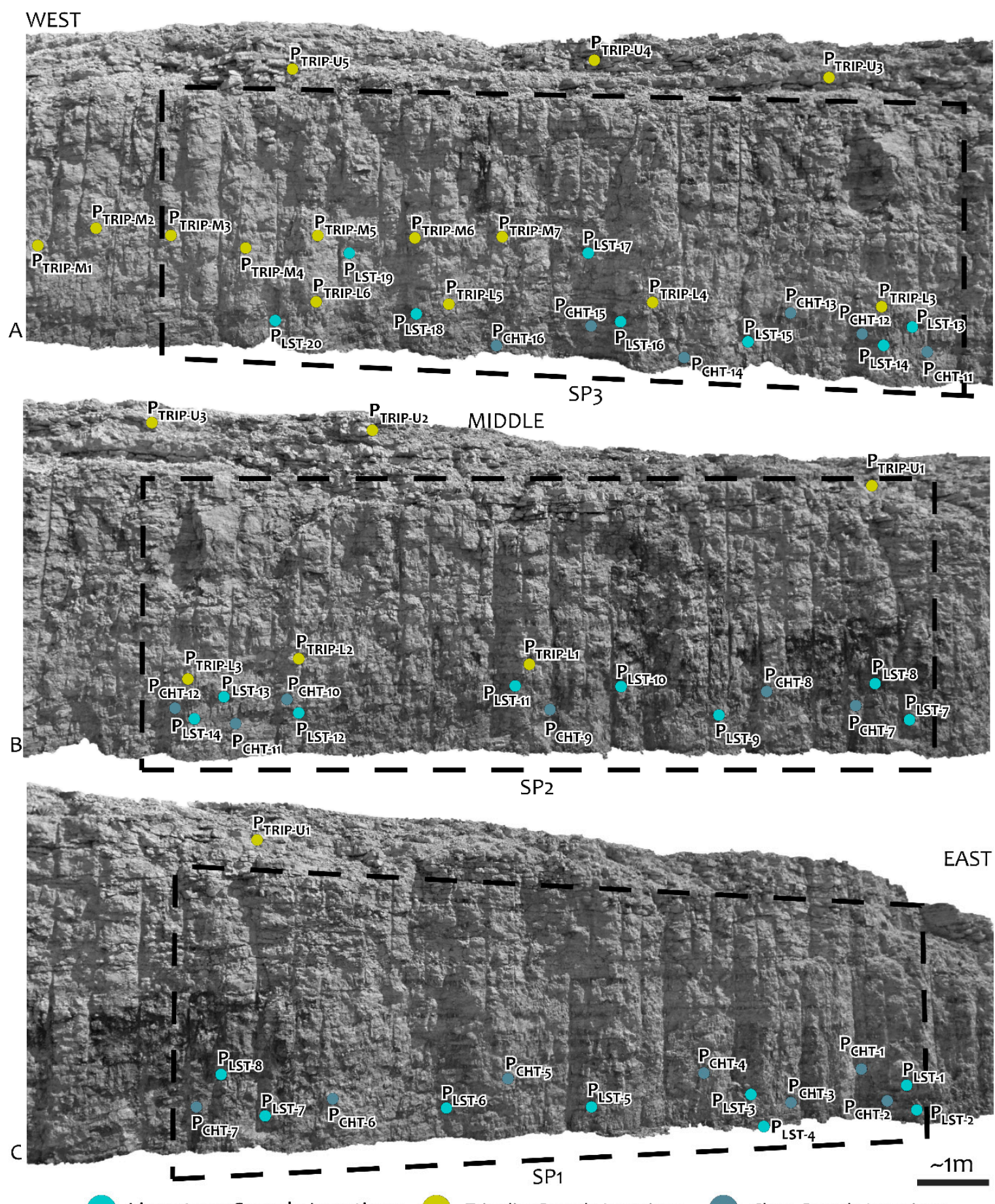

Limestone Sample Locations

Tripolite Sample Locations

Chert Sample Locations

Figure 5. Field sampling locations on the investigated roadcut. Collected sample names were abbreviated as TRIP, LST, and CHT for tripolite, limestone, and chert, respectively. The subscripts in the tripolite sample names refer to samples collected from the upper (U), middle (M), and lower (L) levels of the roadcut. The dashed lines show the extent of the ground-based hyperspectral images from (A) Scan Position 3 (SP3) to the west, (B) SP2 in the middle, and (C) SP1 to the east of the roadcut. The digital images are courtesy of Google Earth Pro (Image data: Google, Image date: July 2014). 


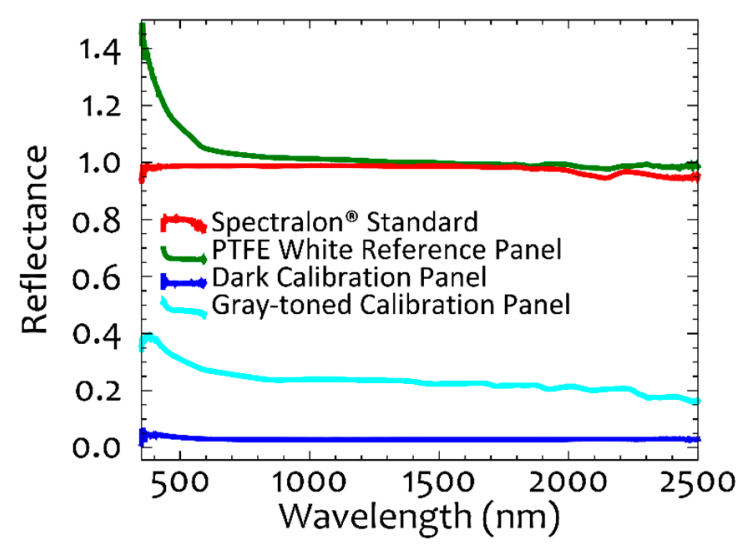

Figure 6. Laboratory reflectance spectroscopy results of white reference panel and custom-made calibration panels with respect to Labsphere Spectralon ${ }^{\circledR}$ standard. The reflectance properties of the PTFE white reference panel are very similar to those of the Labsphere Spectralon ${ }^{\circledR}$ except the shorter wavelengths of the visible portion of the EMS.

\subsection{Laboratory Reflectance Spectroscopy}

Laboratory reflectance spectroscopy was performed using the ASD FieldSpec Pro spectroradiometer so as to (i) provide information on the general spectral pattern and features of the samples based on some basic observations and (ii) extract representative end-member spectra of the major lithological units, i.e., chert, limestone, and tripolite. Laboratory reflectance spectroscopy data were collected from different parts of all 54 samples, focusing on homogeneous areas in terms of color and texture. The mean spectrum $(\mu)$ and standard deviation $(\sigma)$ of the samples were calculated for each lithology. Subsequently, in order to assess the spectral variability within the sample population, instead of using only the mean spectrum, four statistically significant sample spectra (one and two standard deviations around the mean) were obtained, accounting for $95.45 \%$ variability in the sample population.

\subsection{Ground- and Laboratory-Based Hyperspectral Image Pre-Processing}

The raw hyperspectral images require pre-processing so as to prepare the data for analysis and spectral mapping. Pre-processing include dark current signal removal, image/sensor artifact removal, atmospheric compensation and reflectance conversion, and noise reduction [44]. The hyperspectral images were mainly processed using the standard tools available in ENVI 5.3 (Exelis Visual Information Solutions Inc.). Additionally, in-house solutions for image artifact corrections were developed in the MATLAB 2014a (The Mathworks Inc.).

All hyperspectral images show significant image artifacts associated with push-broom scanning [45], some of which can only be seen at different stages of processing. Therefore, it is recommended to perform artifact removal on affected products as it becomes more evident [46]. Hyperspectral images were first corrected for the dark current signal caused by the response of an image sensor, even though the shutter is closed and the sensor is not actively irradiated. For this, an average dark frame was obtained from the dark image, collected with no incident light and subtracted from each image frame. This also removes the systematic striping in the raw hyperspectral images caused by the non-uniform response between individual elements along the sensor line. Poor performance of individual elements in the 2D sensor array causes outliers (bad pixels), unusually high or low values in the spectral domain, which result in bad image lines along-track in corresponding bands. Some of these outliers may not be identified or corrected in the dark-subtracted image but become more evident after reflectance conversion. For this reason, the bad pixel correction has been done in two steps. First, on the dark-subtracted image the bad image lines were identified in the spatial domain and replaced by the mean of the adjacent lines above and below. Second, the bad 
pixels were identified in the spectral domain and interpolated using linear interpolation only after reflectance conversion.

Although the acquisition takes $45-60 \mathrm{~s}$ for each individual image, due to changes in sun intensity mostly caused by viewing angle variation along image frame and cylindrical image geometry of the cameras, slight brightness gradients can be observed in the images along- and across-track. Following the bad pixel correction in the spatial domain, the brightness gradient of the images was evaluated for each spectral band separately. The brightness gradient in the hyperspectral images can be described using a second-order polynomial and from the polynomial correction coefficients can be calculated and applied (multiplicative or additive compensation) so as to normalize the gradient $[47,48]$. This approach is implemented in ENVI as the Cross-track Illumination Correction, which was applied to hyperspectral data using multiplicative compensation. For the ground-based data the correction was first applied across-track using first-order polynomials. Subsequently, along-track correction was applied using second-order polynomials. For laboratory-based data the correction was applied across-track only using first-order polynomials as the illumination geometry does not change along-track. For atmospheric compensation and reflectance conversion, Empirical Line Calibration [49] was used. Empirical line calibration uses a band-wise linear regression to relate image pixel digital numbers (DNs) to reflectance values estimating correction coefficients (i.e., gain and offset values). Using gain and offset values for correction can be considered as equivalent to removing the solar irradiance and the atmospheric path radiance [44]. It is recommended to use two to four targets with large spectral contrast (i.e., dark and bright) so as to estimate correction coefficients for better results [49]. Hence, three calibration panels with known reflectance $(\sim 3 \%, \sim 20 \%$, and $\sim 99 \%)$ were used for empirical line calibration. Following the identification and correction of bad pixels in the spectral domain, the subsequent reflectance images were filtered using a second-order polynomial smoothing filter (Savitzky-Golay filtering) with a width of eight bands, so as to reduce noise in the spectra [50]. Savitzky-Golay filtering preserves the shape and features of the spectrum while maximizing the noise removed from the spectrum [51]. Maximum Noise Fraction (MNF) transformation [52] was applied to filtered reflectance images so as to enhance the inherent variability between spectral bands and remove random noise. The spatially coherent, noise-free components with high eigenvalues (roughly $>3.0$ representing $>0.6$ spatial coherence) representing most of the variance in the image were segregated from the noisy data. The first 12-17 MNF components were found to be spatially coherent for both ground- and laboratory-based hyperspectral images. Subsequently, an inverse MNF transformation was applied, using only the spatially coherent components to convert the data back to its spectral domain providing noise-free reflectance images. The inverse MNF transformation resulted in 170 bands for ground-based hyperspectral images (excluding the wavelengths affected by atmospheric absorption) and 255 bands for laboratory-based hyperspectral images. Following the inverse MNF transformation, the signal-to-noise ratio (SNR) of the images were calculated by dividing the mean by standard deviation over homogeneous areas [53] such as calibration panels. The SNR is around 65:1 (averaged excluding the wavelengths affected by atmospheric absorption) for ground-based hyperspectral images and 150:1 for laboratory-based hyperspectral images.

\subsection{Spectral Mapping}

\subsubsection{Spectral End-Member Extraction}

The end-member concept has been widely used in compositional identification and classification of hyperspectral data. The concept relies on the assumption that spectral variability of an image pixel should be explained with a set of relatively pure end-members [54]. End-members can be selected from spectral libraries built using field and/or laboratory measurements providing known end-member spectra or can be extracted from the purest pixels in the image providing derived end-member spectra [54]. For this study, known end-member spectra of major lithological units of the outcrop were obtained from the laboratory reflectance spectroscopy as described previously, and 
thus will be regarded as laboratory spectra (or ASD-Lab for short). Subsequently, the laboratory spectra were resampled so as to match the hyperspectral sensor's band wavelengths. Derived end-member spectra were extracted directly from the hyperspectral images for the purpose of image classification. The end-member spectra from both ground- and laboratory-based images were extracted from user-defined regions of interest (ROI). In order to identify the most spectrally pure pixels and define the ROIs in the ground-based images a statistical approach, i.e., pixel purity index, was used on the spatially coherent MNF components. The materials within these pixels were identified in the noise-free reflectance images based on the interpretations and comparison of absorption features of the major lithological units, thus the ASD-Lab spectra were used as a guide. The end-member spectra extracted from the ground-based hyperspectral images will be regarded as the field image spectra (or IS-Field spectra for short). In order to define the ROIs in the laboratory-based images the spots used for laboratory reflectance spectroscopy analysis were found on the noise-free reflectance images. Subsequently, the ROIs were defined around these spots. The end-member spectra extracted from the laboratory-based hyperspectral images will be regarded as the laboratory image spectra (or IS-Lab spectra for short).

\subsubsection{Hyperspectral Image Classification}

The hyperspectral image classification was performed using two established classification methods, Spectral Feature Fitting $[55,56]$ using the laboratory spectra and Mixture-tuned Match Filtering [57-59] using the field image spectra and laboratory image spectra for ground- and laboratory-based images, respectively. Spectral Feature Fitting (SFF), as a whole-pixel approach, has been commonly used for hyperspectral image classification [60,61]. As an absorption feature-based algorithm, SFF compares the spectral features between an image pixel and a reference spectrum. The algorithm takes continuum-removed image and reference spectra and evaluates their fit using a least-squares technique. For this, the reference spectrum is scaled so as to match the image pixel spectrum. A closer match, i.e., higher spectral similarity, is represented by a better fit. The algorithm considers only the major pixel components; therefore, sub-pixel abundances, i.e., mixtures, cannot be detected (hard classification). As it takes specific absorption features, not the shape of the overall spectra, and the reference spectrum is scaled so as to match to that of the image pixel, SFF is sensitive to subtle absorption features of the end-members given the accurate reference spectrum $[62,63]$. Thus, SFF benefits from application of continuum removal over narrower wavelength ranges that cover diagnostic absorption features. In this study, however, the entire wavelength range, except the wavelengths affected by the atmosphere, was used as the focus of the analysis was on the bulk lithology rather than individual minerals. Mixture-tuned match filtering (MTMF), as a sub-pixel approach, has also been commonly used for hyperspectral image classification [64,65]. Unlike SFF, however, it is a partial spectral unmixing algorithm used to map sub-pixel abundances of user-defined end-members (soft classification). The algorithm maximizes the response of the end-member while suppressing the response of the background. For each respective end-member, it provides a score image as a proportion of the end-member and an infeasibility image in noise sigma units, which is used to reduce the number of false positives. MTMF requires isotropic, unit variance data, such as MNF transformed data, as input. Therefore, MTMF was performed using only the spatially coherent MNF components.

\section{Results}

\subsection{Laboratory Reflectance Spectroscopy}

The reflectance spectra of the major lithological units, i.e., chert, limestone, and tripolite, were collected from the areas on the samples with seemingly homogeneous color and texture. The results of the laboratory reflectance spectroscopy results are given in (Figure 7) as the mean $(\mu)$ and plus or minus two standard deviation $( \pm 2 \sigma)$ around the mean accounting for the spectral variability. 
The general spectral pattern and features of the samples can be seen in the laboratory reflectance (ASD-Lab) spectra. Bluish-gray chert and dark gray limestone samples show spectral properties typical for these lithologies, with lower overall spectral profiles compared to those of pale yellow tripolite. Overall, pale yellow tripolite samples generally have a higher reflectance profile (around $50 \%$ ) than that of chert (around 15\%) or limestone (around 25\%). All of the laboratory spectra, regardless of the lithology, show absorption features at around $1900 \mathrm{~nm}$, which is consistent with the $\mathrm{H}_{2} \mathrm{O}$ content in the samples $[12,66]$. Additionally, tripolite samples show $\mathrm{H}_{2} \mathrm{O}$ absorption at around $1400 \mathrm{~nm}$, which is weaker in chert samples and almost absent in limestone samples. Based on the relative strength of characteristic $\mathrm{H}_{2} \mathrm{O}$ absorption features, particularly at around $1900 \mathrm{~nm}$, tripolite samples have the highest $\mathrm{H}_{2} \mathrm{O}$ content, whereas chert samples have the second highest $\mathrm{H}_{2} \mathrm{O}$ content.
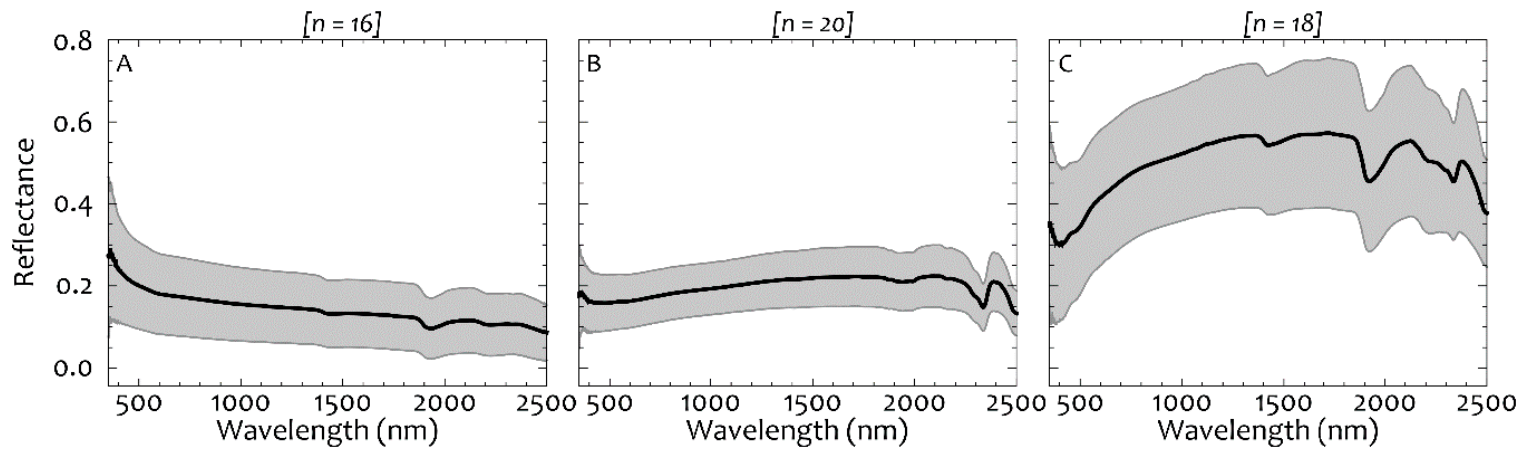

Figure 7. Reflectance spectroscopy results of (A) chert, (B) limestone, and (C) tripolite samples. Solid black lines depict the mean spectrum of each lithology whereas gray areas show $\pm 2 \sigma$ around the mean, accounting for $95.45 \%$ variability. The number of samples analyzed is indicated by [n].

Chert samples have higher reflectance in the shorter wavelengths around $400 \mathrm{~nm}$, which gives its bluish color (Figure 7A). Towards the longer wavelengths, chert spectra are flattened at around $600 \mathrm{~nm}$ and become non-descriptive except for an absorption feature at around $1900 \mathrm{~nm}$ associated with $\mathrm{H}_{2} \mathrm{O}$ and weaker absorption features at around $1400 \mathrm{~nm}$ and $2200 \mathrm{~nm}$, consistent with $\mathrm{H}_{2} \mathrm{O}$ and $\mathrm{Al}-\mathrm{OH}$, respectively [12]. Limestone samples have a non-descriptive overall spectra except an absorption feature at around $1900 \mathrm{~nm}$ associated with $\mathrm{H}_{2} \mathrm{O}$ and rather strong absorption features at around $2340 \mathrm{~nm}$ and $2500 \mathrm{~nm}$ associated with $\mathrm{CO}_{3}$ (e.g., calcite) [67] (Figure 7B). Similarly, tripolite samples showed rather strong absorption features at around $2340 \mathrm{~nm}$ and $2500 \mathrm{~nm}$, indicating the presence of $\mathrm{CO}_{3}$ (Figure 7C). Tripolite samples have lower reflectance in the shorter wavelengths, with an absorption feature at around $400 \mathrm{~nm}$ and a weaker absorption feature around $500 \mathrm{~nm}$. These spectral features are similar to those of $\mathrm{Fe}^{3+}$ oxide and oxide hydroxide between $400 \mathrm{~nm}$ and $550 \mathrm{~nm}$ [68]. Additionally, tripolite samples showed absorption features at around $2200 \mathrm{~nm}$ consistent with Al-OH (clay) minerals [12].

Some of the details in the reflectance spectra can only be observed on the continuum-removed (normalized or convex-hull removed) spectra. For this, using the ASD-Lab spectra, five statistically representative spectra for each lithology (accounting for spectral variability of the sample population) were calculated using one and two standard deviations around the mean spectrum (Figure 8A) and continuum-removal was applied for shortwave infrared wavelengths between $900 \mathrm{~nm}$ and $2500 \mathrm{~nm}$ (Figure 8B). The spectral properties described above can be seen in more detail on the continuum-removed spectral profiles. In addition, some weaker absorption features have been identified on the continuum-removed spectral profiles. Chert samples have, though weak, absorption features consistent with $\mathrm{CO}_{3}$ at around $2340 \mathrm{~nm}$ and $2500 \mathrm{~nm}$ (Figure 8(B1)). The absorption feature centered at $2210 \mathrm{~nm}$ is indicative of $\mathrm{Al}-\mathrm{OH}$ clay minerals in the chert samples [69,70]. Continuum-removed spectra of limestone samples showed spectral features at around $1750 \mathrm{~nm}$, $1870 \mathrm{~nm}, 1980 \mathrm{~nm}$, and $2160 \mathrm{~nm}$, which can easily be related to the characteristic absorption caused by 
$\mathrm{CO}_{3}[12,71]$ (Figure 8(B2)). Typically, $1870 \mathrm{~nm}$ and $1980 \mathrm{~nm}$ absorption features cannot be observed using passive sensors since they are almost completely affected by the atmospheric absorption. Continuum-removed spectra showed clay mineral absorption feature in the tripolite samples at around $2210 \mathrm{~nm}$, indicating Al-OH minerals (Figure 8(B3)). An additional absorption feature can be observed at around $2290 \mathrm{~nm}$ which indicates presence of Fe-OH minerals [69,72]. For a more detailed analysis, continuum removal was applied to a narrower wavelength range, between $2128 \mathrm{~nm}$ and $2378 \mathrm{~nm}$, which covers the specific diagnostic absorption features of $\mathrm{Al}-\mathrm{OH}$ and $\mathrm{CO}_{3}$ so as to evaluate their relative content in the samples (Figure 8C). Based on the relative depths of diagnostic absorption features at around $2210 \mathrm{~nm}$ and $2340 \mathrm{~nm}, \mathrm{Al}-\mathrm{OH}$ and $\mathrm{CO}_{3}$ contents vary between chert samples (Figure 8(C1)). The $\mathrm{CO}_{3}$ content in limestone samples is almost invariable and these samples do not show any absorption feature associated with Al-OH content unlike chert and tripolite samples (Figure 8(C2)). Tripolite samples show a greater variability in $\mathrm{Al}-\mathrm{OH}$ and $\mathrm{CO}_{3}$ content (Figure 8(C3)).
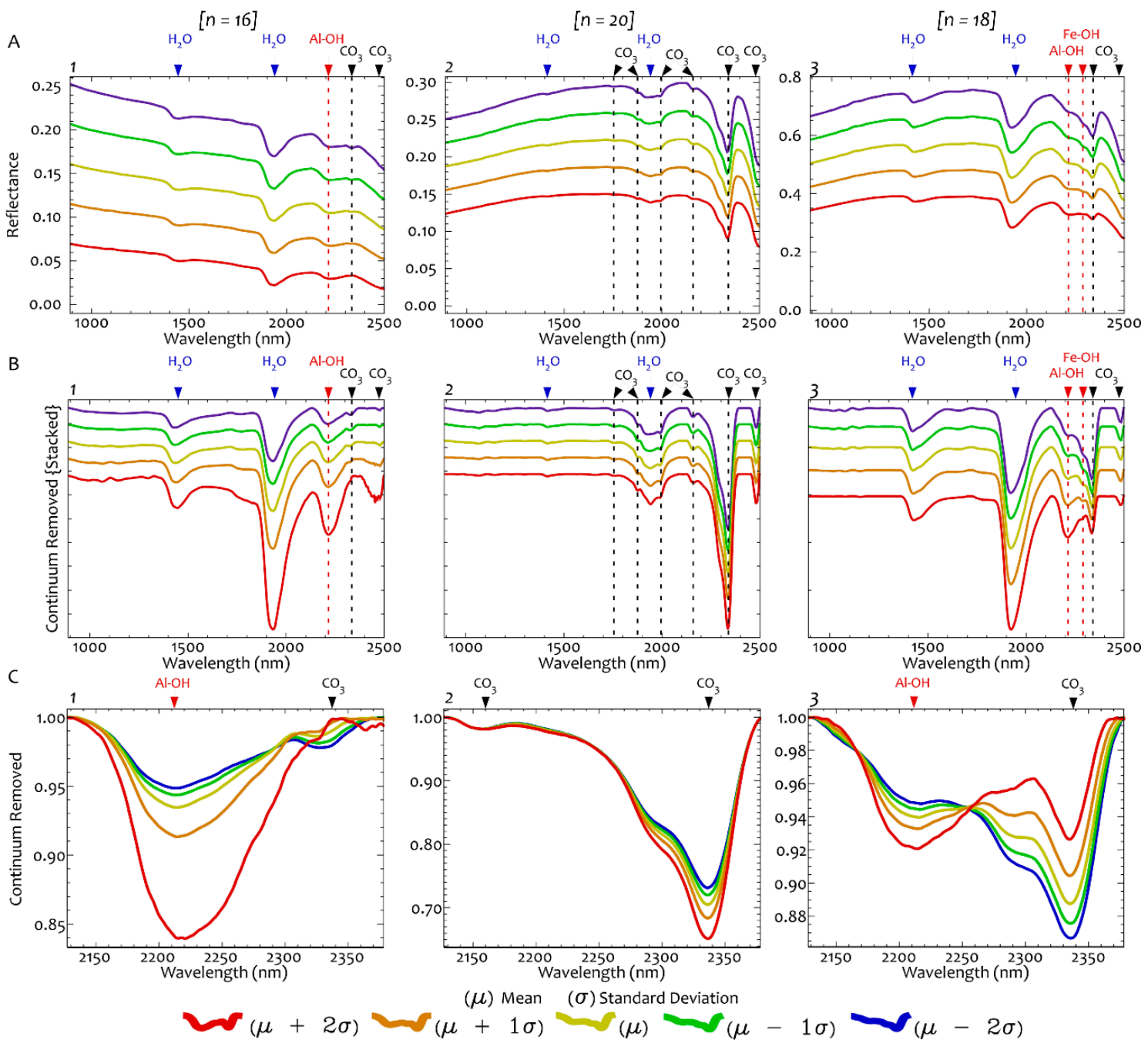

$\quad(\sigma)$ Standard Deviation

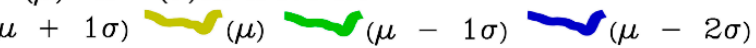

Figure 8. (A) Representative reflectance spectra of chert (A1), limestone (A2), and tripolite (A3) calculated using standard deviation $(\sigma)$ around the mean $(\mu)$. (B) Continuum removed spectra of chert (B1), limestone (B2), and tripolite (B3). The spectra are offset by 0.1 for clarity. (C) Spectra of chert (C1), limestone (C2), and tripolite (C3) with continuum removed over 2128-2378 nm range. The number of samples analyzed is indicated by $[\mathrm{n}]$.

Tripolite samples collected from different levels of the roadcut were further analyzed individually, particularly for $\mathrm{Al}-\mathrm{OH}$ and $\mathrm{CO}_{3}$ content, so as to evaluate the spectral variation in tripolite samples, 
which in turn could help us better understand the spatial variation of tripolitization in the investigated roadcut. For this, in addition to the wavelength range between $2128 \mathrm{~nm}$ and $2378 \mathrm{~nm}$, continuum removal was applied over even narrower wavelength ranges between $2128 \mathrm{~nm}$ and $2302 \mathrm{~nm}$, and $2303 \mathrm{~nm}$ and $2373 \mathrm{~nm}$ for $\mathrm{Al}-\mathrm{OH}$ and $\mathrm{CO}_{3}$, respectively (Figure 9).
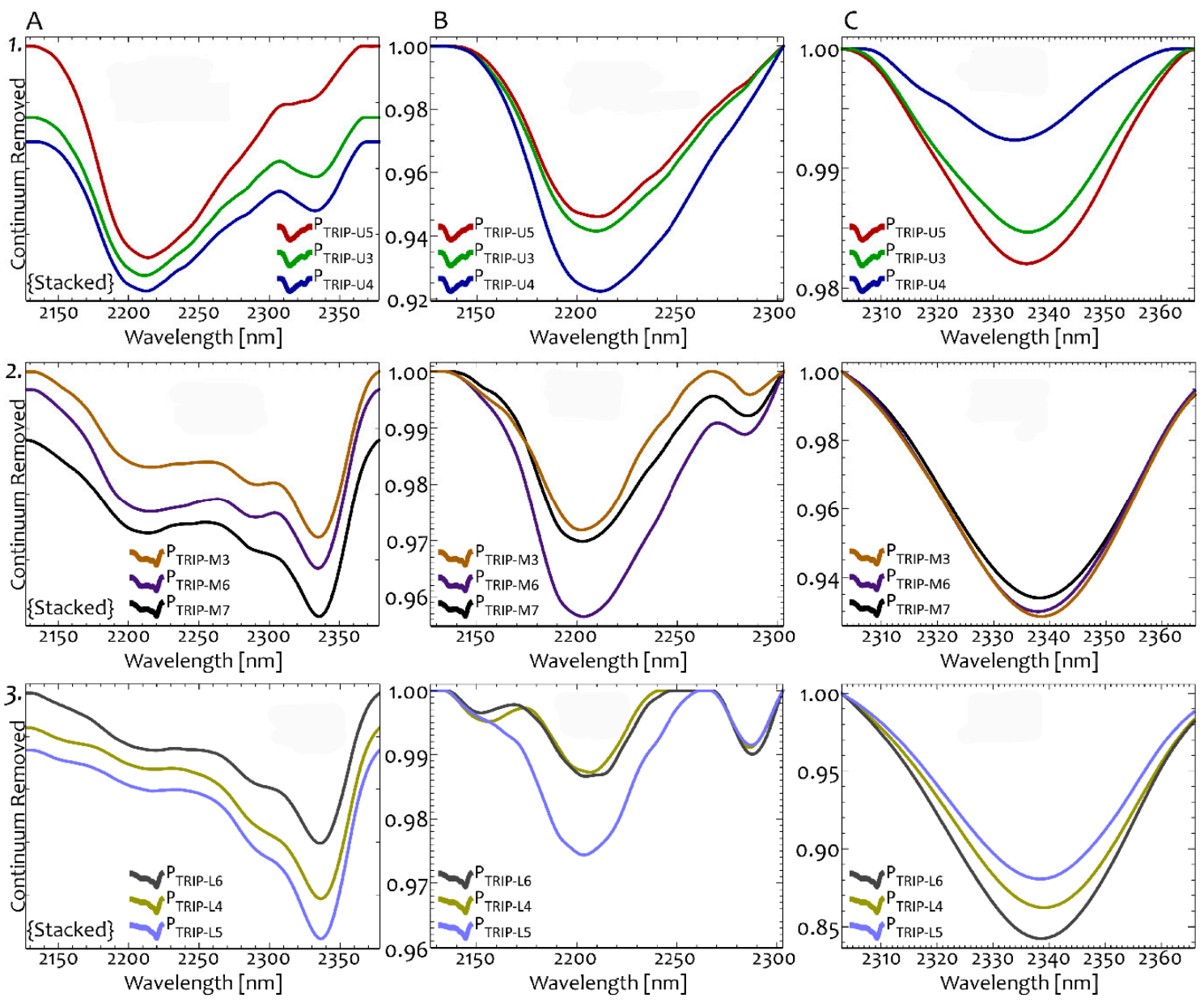

Figure 9. Continuum removed spectra of selected tripolite samples collected from (1) higher levels, (2) middle levels, and (3) lower levels of the roadcut, where accessible. Continuum removal was applied over the wavelength ranges of (A) $2128-2378 \mathrm{~nm}$, (B) 2128-2302 nm, and (C) 2303-2373 nm.

Tripolite samples collected from stratigraphically higher levels of the roadcut (samples $\mathrm{P}_{\mathrm{TRIP}-\mathrm{U} 1}$ through $\mathrm{P}_{\text {TRIP-U5 }}$ ) have higher $\mathrm{Al}-\mathrm{OH}$ content and lower $\mathrm{CO}_{3}$ content based on the relative depth of the diagnostic absorption features at around $2210 \mathrm{~nm}$ and $2340 \mathrm{~nm}$, respectively (Figure 9(A2,A3)). Relative $\mathrm{Al}-\mathrm{OH}$ absorption depths in the samples from the upper levels range between 0.054 and 0.078 and relative $\mathrm{CO}_{3}$ absorption depths range between 0.008 and 0.018 . Conversely, tripolite samples from stratigraphically lower levels (samples $\mathrm{P}_{\text {TRIP-L1 }}$ through $\mathrm{P}_{\text {TRIP-L6 }}$ ), where tripolite grades into cherty limestone rocks of the Reeds Spring Formation, have higher carbonate content and lower Al-OH content. Relative Al-OH absorption depths in the samples from the lower levels range between 0.002 and 0.026, and relative $\mathrm{CO}_{3}$ absorption depths range between 0.097 and 0.160 . For each tripolite sample, wavelength position and relative depth of diagnostic absorption features of $\mathrm{Al}-\mathrm{OH}$ and $\mathrm{CO}_{3}$ were quantified and tabulated in Table 2. Additionally, the relative Al-OH absorption feature depths from 18 tripolite samples were plotted against the relative $\mathrm{CO}_{3}$ absorption depths so as to show the trend of variation amongst tripolite samples (Figure 10). 
Table 2. Absorption feature parameters (wavelength position and relative depth) of $\mathrm{Al}-\mathrm{OH}$ and $\mathrm{CO}_{3}$ obtained from the continuum removed spectra of tripolite samples.

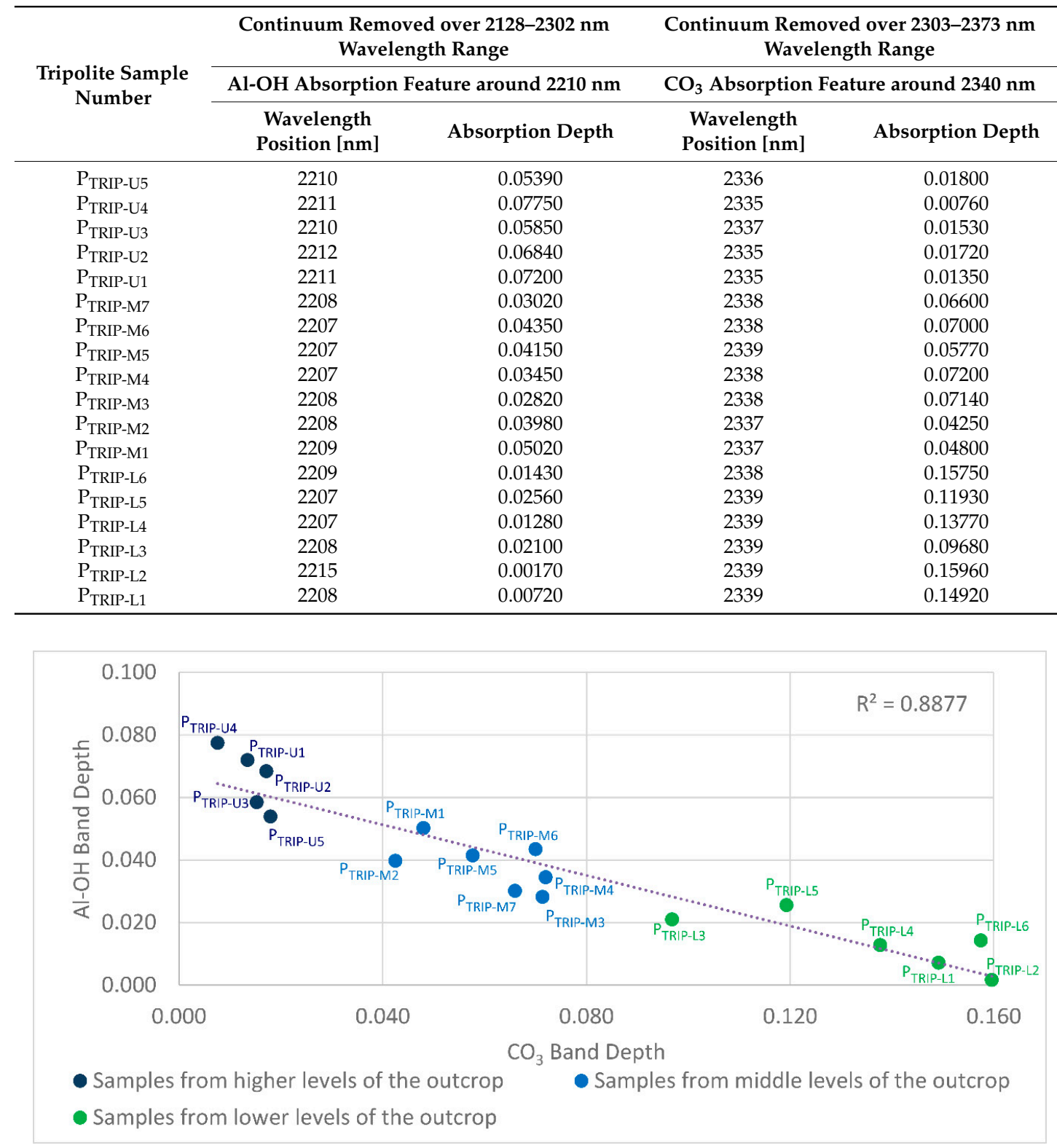

Figure 10. Relative Al-OH absorption feature depths versus relative $\mathrm{CO}_{3}$ absorption depths from 18 tripolite samples collected from the investigated roadcut. The samples were divided into three clusters and color coded based on the levels they were collected.

Image end-member spectra were extracted from both ground- and laboratory-based images for comparison and image classification. A comparison between ASD-Lab, IS-Field, and IS-Lab end-member spectra is given in Figure 11. The major SWIR absorption features of the lithological units in the outcrop can be seen in all three spectra. Some of the weaker absorption features, however, are more prominent in the ASD-Lab and IS-Lab spectra than in the IS-Field spectra. The mean ASD-Lab and IS-Lab spectra of samples from major lithological units show higher consistency. In comparison, the consistency between the ASD-Lab and IS-Field spectra is relatively lower, mainly due to the overall shape of the spectra. Nevertheless, SFF classification using the ASD-Lab end-member spectra was performed for both laboratory- and ground-based hyperspectral data as the SFF classification does not take the overall shape into account. 


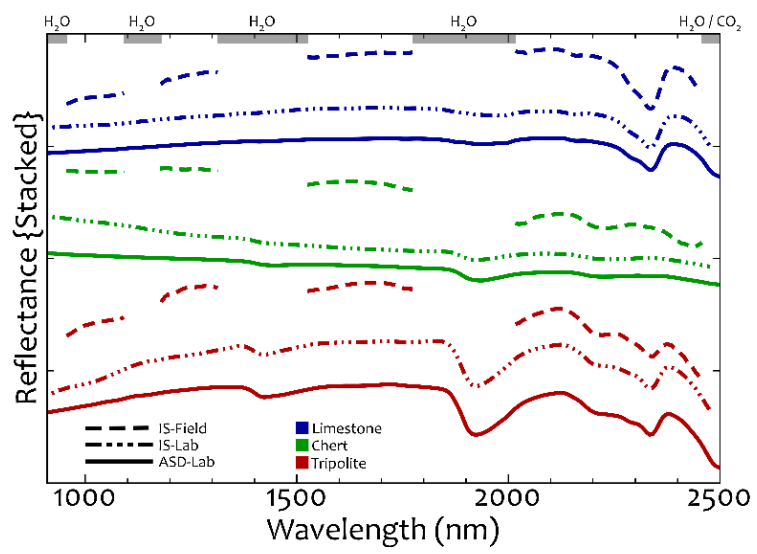

Figure 11. Comparison of mean chert, limestone, and tripolite spectra obtained from laboratory reflectance spectroscopy ( $A S D$ - Lab spectra), extracted from laboratory-based hyperspectral images (IS-Lab spectra), and extracted from ground-based hyperspectral images (IS-Field spectra). Wavelengths affected from the atmospheric absorption, indicated as gray blocks, are masked in the IS-Field spectra. The spectra are stacked by 0.1 offset for clarity.

\subsection{Hyperspectral Image Classification}

Hyperspectral images from scan positions approximately $15 \mathrm{~m}$ apart along the roadcut were collected so as to cover a greater extent of exposed rocks (approximately $65 \mathrm{~m}$ long and $11 \mathrm{~m}$ composite thickness). Collected images and relative positions of these images with respect to each other are given in Figure 12A as false color composites. The effect of cylindrical image geometry manifests itself as evident geometric distortion in the hyperspectral images. The spatially coherent MNF components are also given in false color composites (Figure 12B). Color composites created using spatially coherent MNF bands have proven to be useful for initial interpretation and end-member identification in hyperspectral images [73]. However, since the transformation is unique for each image, individual MNF components of different images and created color composites cannot be compared directly between the images [19].
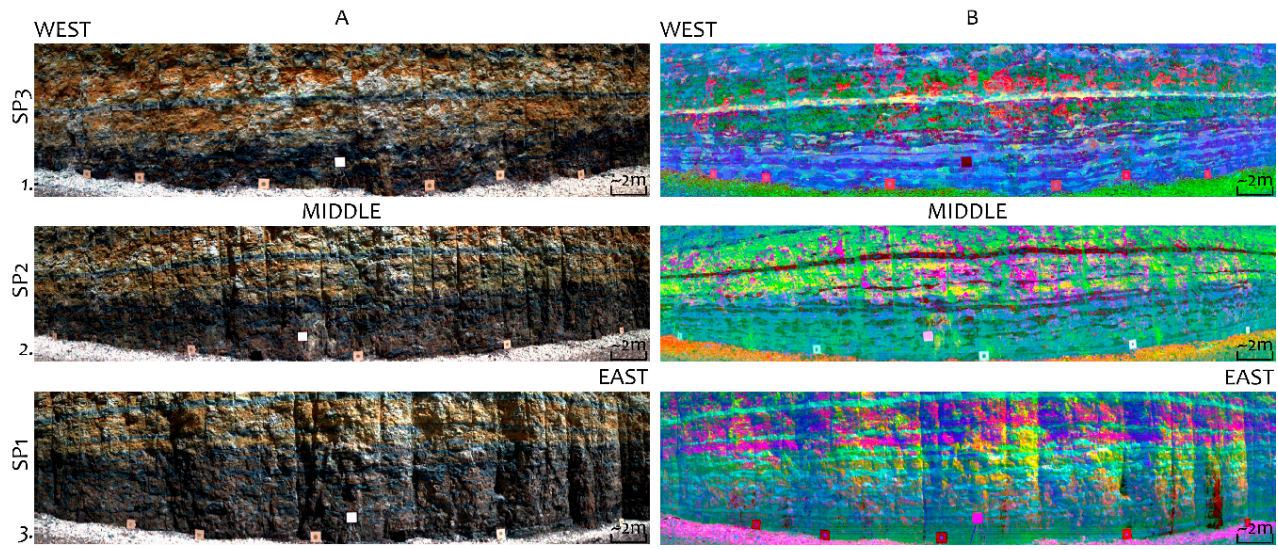

Figure 12. (A) False color hyperspectral images of the roadcut along US-71 Hwy near Pineville from scan positions 3 to the West to 1 to the East (SP3-SP1), spectral bands 1086, 1554, and $2033 \mathrm{~nm}$ are displayed in red, green, and blue (RGB). (B) False color Maximum Noise Fraction (MNF) images based on (A) with bands (5, 1, and 2), (6, 5, and 2), and (5, 2, and 6) displayed in RGB for SP3 to SP1, respectively.

The SFF classification was performed on the noise-free reflectance images using the ASD-Lab end-member spectra obtained from laboratory reflectance spectroscopy. The SFF algorithm results in 
scale and root-mean-square (RMS) images for each respective end-member. Higher scale values accompanied by low RMS values of image pixels represent a better fit to the reference spectra. The end-member scale and RMS images were combined and transferred into binary classification images using 2D scatter plots. The cut-off value for the scale images were determined to be around 0.5 (at least $50 \%$ fit) for each end-member, whereas the RMS values were around 0.03 to 0.05 . Subsequently, post-classification corrections were applied so as to (i) minimize the mottling effect and (ii) suppress isolated pixels within classes using spatial filtering. The SFF results for tripolite, limestone, and chert end-members are given in Figure 13. Although no tripolite was observed in the Lower Reeds Spring during field campaign and sample collection, some pixels, likely to be limestone, were misclassified as tripolite in the lower portion of the outcrop. Further assessment and comparison between classification and reflectance images showed that the misclassified pixels are consistent with pixels affected by shadow due to surface relief. Although their patterns and depths are different, tripolite samples with higher carbonate content and limestone samples both have strong absorption feature at around $2340 \mathrm{~nm}$. Due to the effect of shadow, however, these differences between the spectra are not as distinctive and show similar pattern and depth. Thus, the overlapping absorption features could have affected the classification.

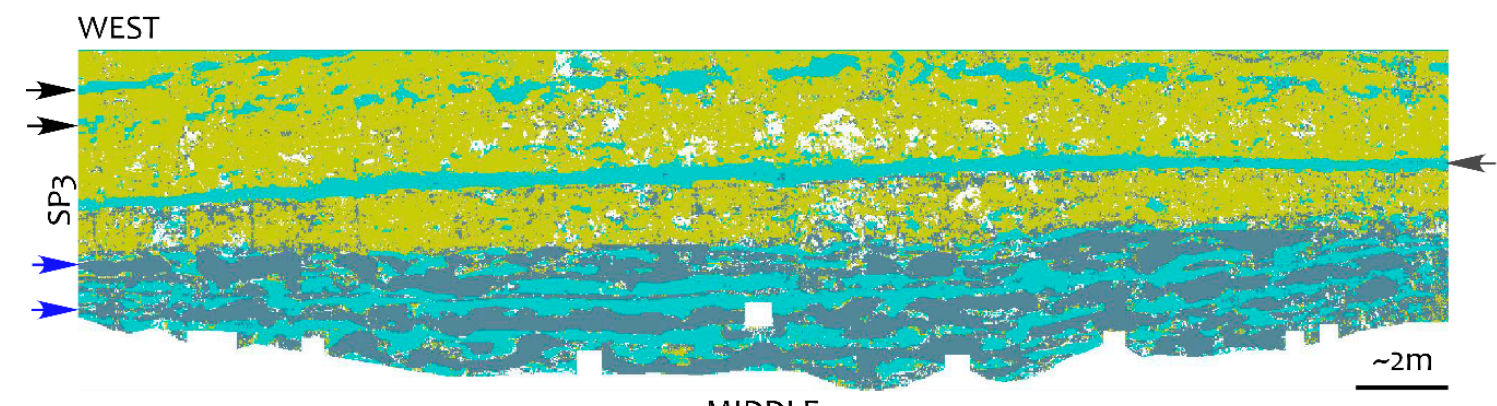

MIDDLE
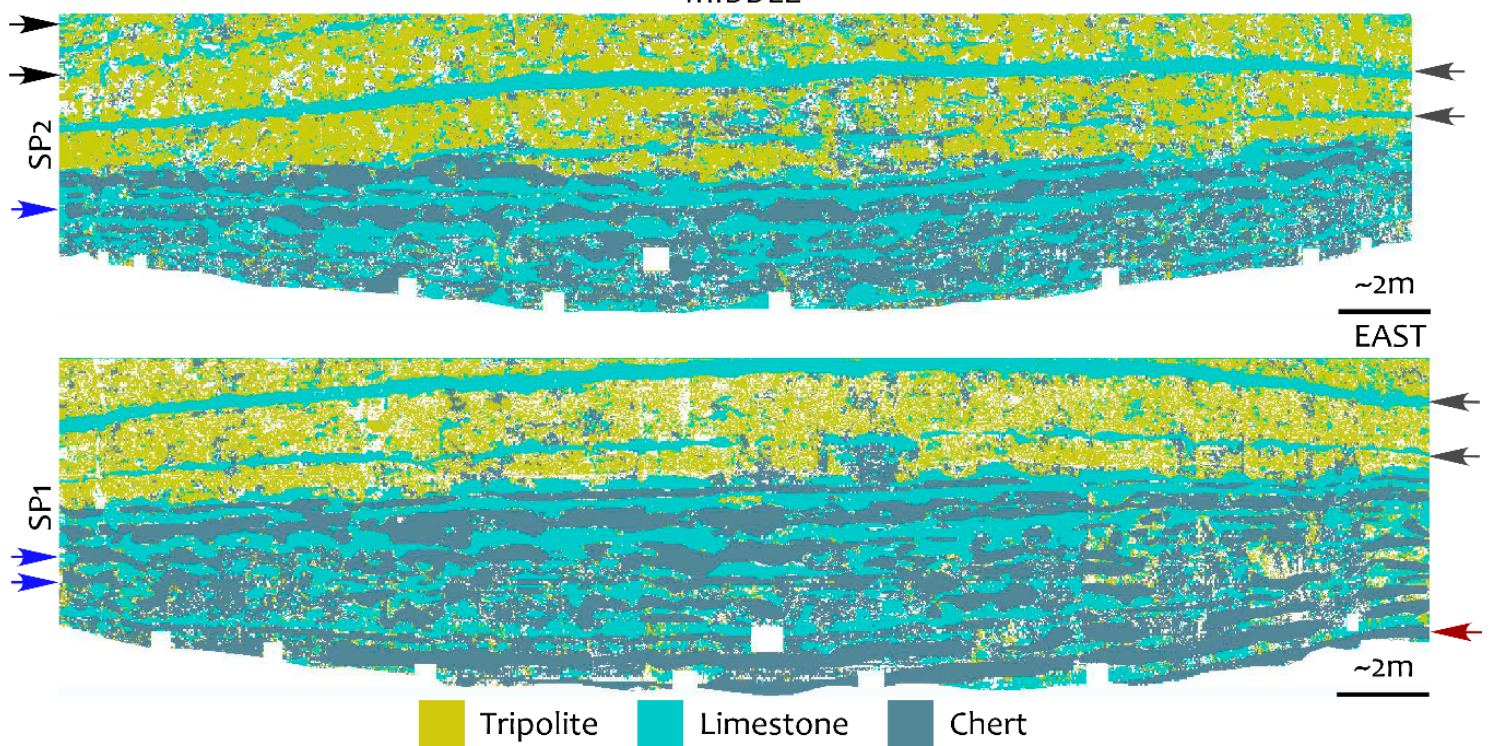

Figure 13. Spectral feature fitting results using ASD-Lab end-member spectra from (SP3) Scan Position 3 to the west, (SP2) Scan Position 2 in the middle, and (SP1) Scan Position 1 to the east of the roadcut. The black arrows show patches of limestone following a linear pattern, the blue arrows show alternating chert and limestone layers with undulating boundaries, the gray arrows show persistent, continuous limestone layers, and the red arrow shows chert and limestone layers with flat boundaries.

Mixture-tuned Match Filtering (MTMF) was performed on spatially coherent MNF components using IS-Field and IS-Lab end-member spectra for ground- and laboratory-based images, respectively. 
For the MNF transformed data, the first 12 to 17 MNF components were found to be spatially coherent (noise-free) given 0.60 coherence threshold for both ground- and laboratory-based data. The score and infeasibility images, as results of MTMF, were combined so as to create single classification images by keeping pixels containing more than $50 \%$ of the respective end-member material with less than $20 \%$ infeasibility (Figure 14). The results of MTMF analysis support and complement the observations obtained from SFF. The MTMF, however, performed better in classifying the pixels affected by shadow than SFF. As calculated scores for these pixels are lower than the defined threshold, they have been removed and not included in the binary classification. Once the binary images were combined in a composite image (Figure 14) pixels identified with similar chert and limestone abundances could be observed as yellow pixels, along chert-limestone boundaries. Unlike SFF, in addition to transferring the result to binary classification, score images as fractions of end-members, were evaluated so as to observe changes in abundance of lithological units, particularly for tripolite. The score images for tripolite are given in Figure 15. The score values were further classified between 0.1 and 1.0 (10\% to $100 \%$ abundance).
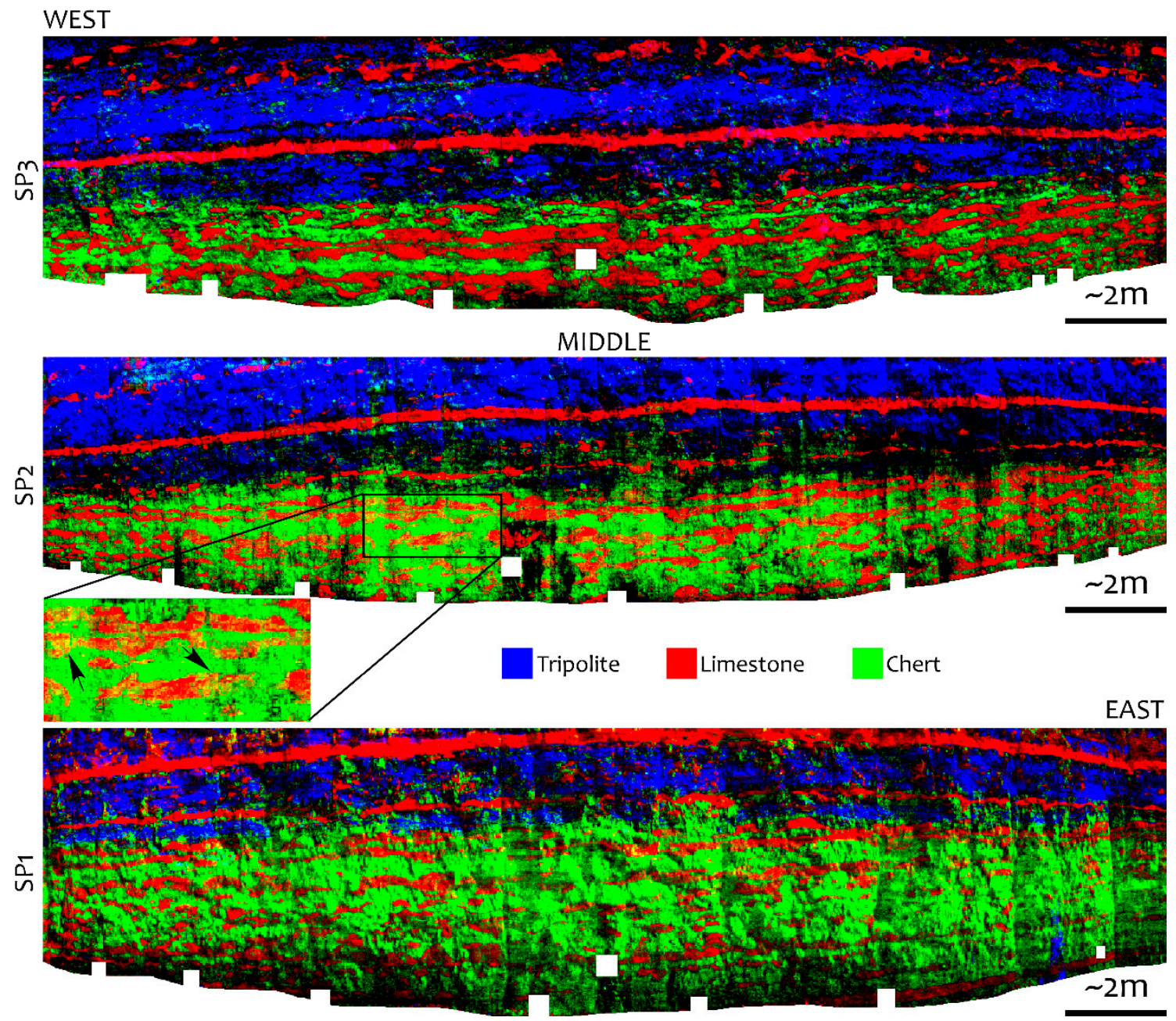

Figure 14. Mixture-tuned match filtering classification results using derived end-member spectra based on spatially coherent MNF components from SP3 to the west to SP1 to the east of the roadcut. The black arrows in the inset image show the areas with similar chert and limestone abundance, characterized by yellow pixels.

The laboratory-based hyperspectral image analysis results of the samples are given in Figure 16. For these images both SFF and MTMF methods have been used. The orientations of the samples were 
considered during collection so as to help interpretation. Similar to outcrop images, major lithological units could easily be detected and differentiated based on SFF using ASD-Lab end-member spectra. The first sample ( $\left.\mathrm{P}_{\text {TRIP-M3 }}\right)$ shown is from a limestone-tripolite contact, right above the transition zone bounded by the first and the most persistent limestone layer (Figure 16(A1)). The SFF results show the contact and remnant limestone fragments within tripolite (Figure 16(A2)). The size of the limestone fragments in this sample is on the order of millimeters. The MTMF results for the same sample show more detail compared to SFF. Right above the limestone-tripolite contact and around the limestone fragments within the tripolite zone, there are areas (which will be regarded as zones of partial leaching) where leaching of the limestone is evident and is yet to be completed (Figure 16(A3)).
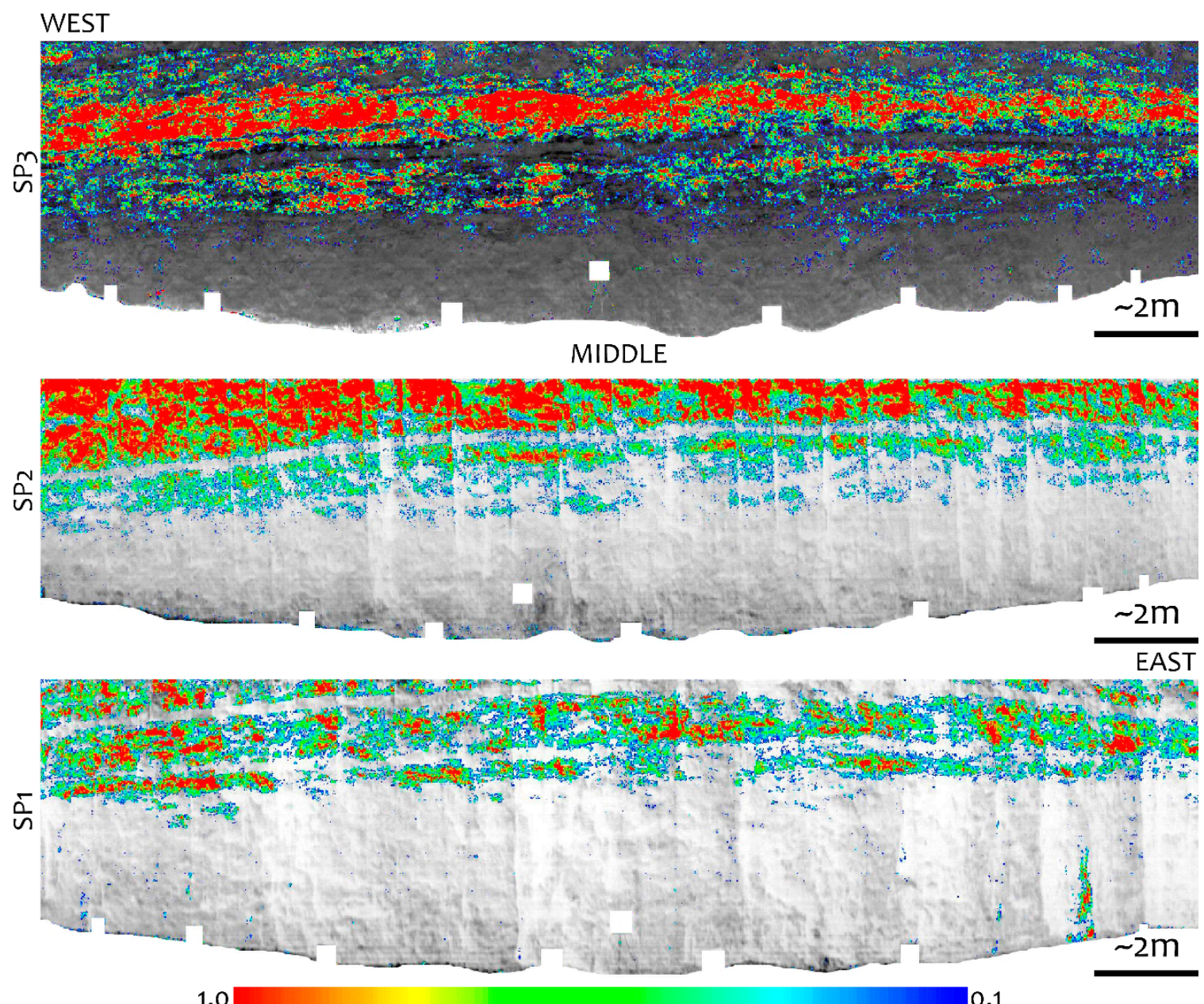

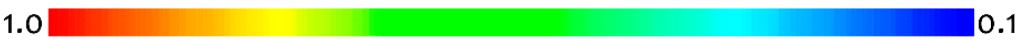

Figure 15. Mixture-tuned match filtering results of tripolite from SP3 to the west to SP1 to the east of the roadcut. The score images were classified between 0.1 and 1.0, with an increment of 0.0625 .

The second sample $\left(\mathrm{P}_{\mathrm{CHT}-13}\right)$ is from a chert-limestone contact in the observed transition zone (Figure 16(B1)). The stylolite observed between limestone and chert indicates the effect of compaction during or following lithification. The upper portion of the sample shows the top-down progression of tripolitization. The third sample ( $\left.\mathrm{P}_{\mathrm{CHT}-2}\right)$ depicts a limestone-chert contact from the interbedded lower Reeds Spring Formation. In this particular sample, a stylolite is not present as the contact is mainly vertical. The results of SFF differentiated chert and limestone clearly using ASD-Lab spectra (Figure 16(C2)). The MTMF method revealed more detailed and interesting results. In the case of MTMF using IS-Lab spectra, two types of chert, slightly different from each other, could be detected (Figure 16(C3)). The second type of chert is more carbonate-rich and surrounds the limestone. 
Considering the syndepositional environment of chert and limestone, this could suggest an interaction during deposition, resulting in relatively higher lime mud content in the siliceous material.
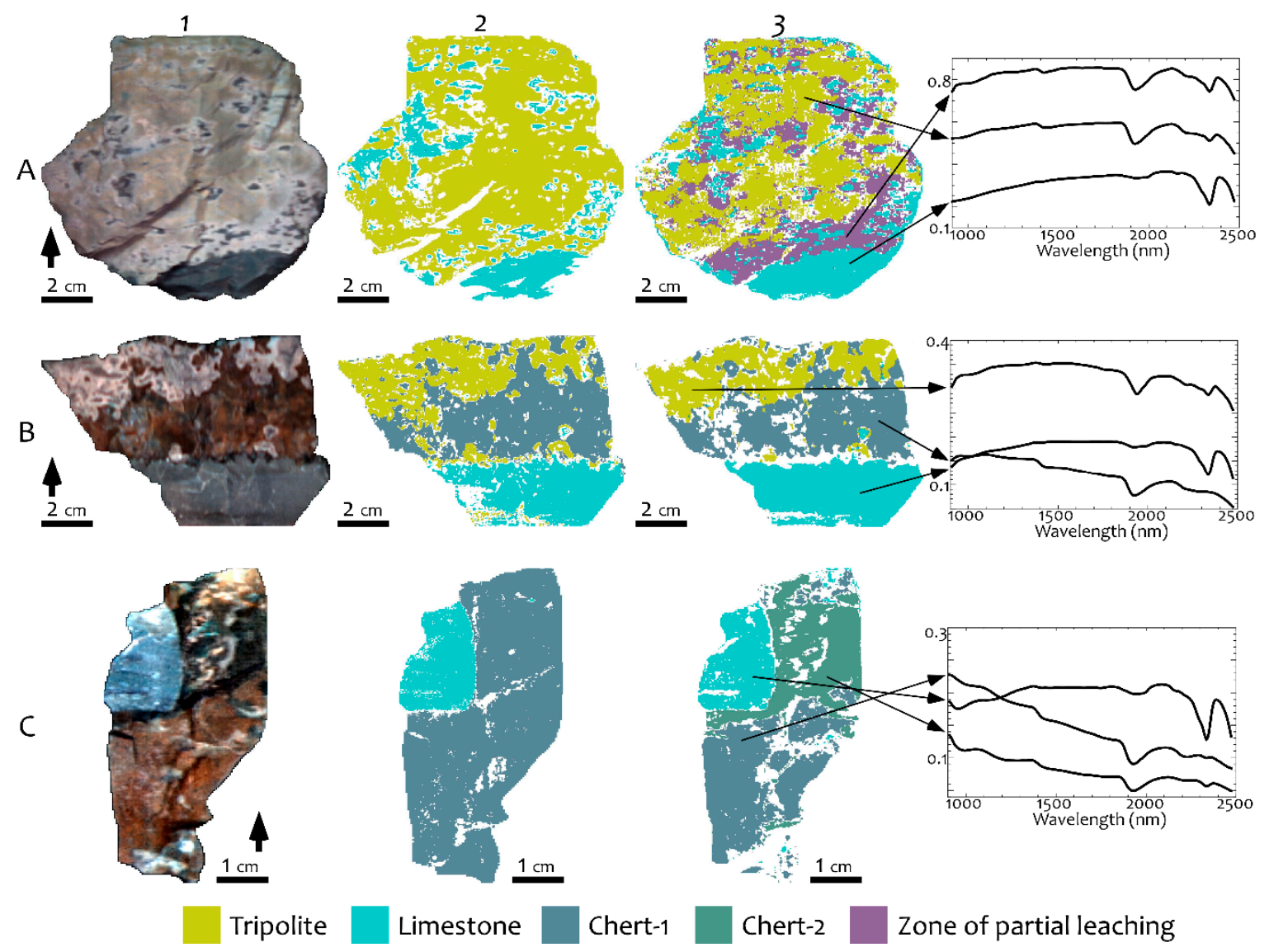

Figure 16. Laboratory-based image analysis results of samples collected during the field campaign. (A) Limestone-tripolite contact right above the persistent limestone layer within tripolite; (B) limestone-chert contact within the transition zone showing stylolite along the contact and early stages of tripolitization in the upper portion; and (C) limestone-chert contact from interbedded Lower Reeds Spring.

\section{Discussion}

A comparison between ASD-Lab, IS-Field, and IS-Lab end-member spectra showed that ASD-Lab and IS-Lab spectra are highly consistent. This can be attributed to the controlled, similar, and stable conditions under which both were collected. The samples used for laboratory reflectance spectroscopy were also used for laboratory-based hyperspectral imaging. Therefore, the exact locations of the samples from which the ASD-Lab spectra were collected could be found in the laboratory-based hyperspectral images with high accuracy (owing to very high spatial resolution) and used for IS-Lab spectra extraction. Thus, the higher consistency between the ASD-Lab and IS-Lab spectra is not all unexpected. The higher spatial resolution provided by both ASD spectroradiometer and the hyperspectral camera could have also helped with minimizing the effect of spectral mixing and promoting consistency between ASD-Lab and IS-Lab end-member spectra. In comparison, the consistency between ASD-Lab and IS-Field spectra is slightly lower. Even though the spectral features are consistent, the overall reflectance and shape of the spectra are slightly different from ASD-Lab spectra. This could be attributed to the way end-member spectra were extracted from the ground-based images. Unlike the IS-Lab spectra, IS-Field spectra were obtained using a statistical approach, i.e., the pixel purity index, to locate spectrally pure end-members. In other words, the sample 
locations on the outcrop were not used for end-member spectra extraction. Thus, the spectrally pure end-members located in the ground-based image do not necessarily coincide with the sampling locations. The surface roughness and relief along the outcrop could also have affected the brightness, which in turn affects the overall shape and reflectance of the spectral signatures in the ground-based images. Also, the spatial resolution of the ground-based images is relatively lower than that of laboratory images, which may promote the effect of spectral mixing. Thus, the pure end-member spectra extracted from the ground-based image and obtained from the laboratory reflectance spectroscopy may not necessarily be the same. Considering these effects, in some cases the spectra obtained from laboratory reflectance spectroscopy, such as ASD-Lab spectra, may not represent the spectral variability of the images as well as image-derived spectra.

Due to cylindrical image geometry, ground-based hyperspectral images show the effect of barrel distortion. That is, straight lines along-track are curved inward and thus images seem "squeezed", particularly towards the extreme edges, whereas the distortion is minimal close to the image center. As a result, the overall trend of the chert and limestone layers is curved inward along-track the image and the observed relative thickness of the strata is squeezed towards the extreme edges of the images. However, the undulating contact between the layers is still evident. Although it is relevant to stratigraphic studies, a 3D geometric reconstruction of the strata is beyond the scope of this study. For such purposes, however, ground-based hyperspectral data can be combined with ground-based Lidar data, providing integrated spectrally and geometrically accurate information.

The SFF results showed that tripolite dominates the top of the Reeds Spring Formation and is easily detected and differentiated from the rest of the Reeds Spring Formation, which is dominated by interbedded limestone and (penecontemporaneous) chert layers. The contact between limestone and chert layers appears to be more or less flat lower in the succession (lower right corner of Figure 13(SP1)), whereas it changes to be more undulating going up in the succession before it grades into tripolite. This undulating contact is indicative of syndeposition and soft sediment deformation due to compaction. That is, siliceous materials were deposited along with carbonates before lithification. Along the chert-limestone contact, stylolites can be observed locally. One such example is presented and discussed based on laboratory-based images of samples. The presence of stylolites suggests that chert and limestone rocks of the Reeds Spring Formation experienced further compaction even after lithification. In support of these interpretations, according to Manger and Shelby [35], penecontemporaneous chert was deposited as an early replacement of carbonate sediments below the sediment-water interface associated with maximum flooding conditions and experienced compaction phenomenon. Thus, formation of chert characterized by compaction and disruptions in bedding in the Reeds Spring formation is syndepositional [35]. Persistent limestone layers can be observed within the tripolite facies particularly close to the transition between tripolite facies and cherty limestone rocks of the Reeds Spring Formation (Figure 13). Going up in the vertical succession, instead of continuous limestone layers, lenses and patches of limestone are observed (Figure 13(SP3)). These patches and lenses, however, follow a linear pattern, suggesting they are remnants of previous, persistent limestone layers. Due to the formation of tripolite, these lenses and patches of limestone could have been formed by leaching during weathering, also suggesting that weathering intensifies in the upper portion of the succession. Analysis of ASD spectra of tripolite samples from different stratigraphic levels indicates decreasing tripolitization downward in the succession. According to the reflectance spectroscopy results, although all tripolite samples show carbonate absorption features, suggesting that tripolite is calcitic, samples higher up in the succession experienced more leaching, and hence lower carbonate content (Table 2). Moreover, higher Al-OH (clay) content indicates that these samples were subjected either to stronger or longer weathering. These suggest a decreasing effect of weathering, thus tripolitization, from top to bottom in the roadcut (Figure 10). In support of this, based on the MTMF results, the abundance of tripolite decreases with depth, indicating a decrease in weathering. The lower tripolite abundance and preserved persistent limestone layers may indicate a transition zone between the highly weathered upper portion and the unaltered lower portion. In the composite 
abundance images, mixed (yellow) pixels indicating similar chert and limestone abundances along chert-limestone boundaries suggest an interaction between chert and limestone during deposition, which can also be observed in one of the samples. Thus, observation from the outcrop hyperspectral images can be substantiated based on laboratory-based hyperspectral images of samples.

It was suggested that tripolitization in the area is a result of groundwater alteration [74] and occurred from the bottom up [39]. The field observations and the results of reflectance spectroscopy and multiscale hyperspectral image analysis in the investigated outcrop suggest otherwise- - that is, tripolite formed from top to bottom. The analysis of both laboratory- and ground-based hyperspectral images suggested a decreasing effect of weathering downwards in the vertical succession. Similar observations have been made from a few other tripolite exposures of the Mississippian outcrop belt in the tristate area [25,31]. Mazzullo et al. [25] observed the gradational contact and downward change in weathering grade in northwest Arkansas. The leaching pattern in the outcrop resulted in limestone patches and lenses in the upper portion of the succession, which, along with the decreasing abundance of tripolite, suggest that the fluid that leached carbonates out and caused weathering should have been flowing from top to bottom. The pattern and geometry of the zones of partial leaching observed in samples are also in support of this interpretation. As the formation of tripolite is a result of weathering (of calcareous chert or siliceous limestone) by meteoric fluids [40], the interpreted fluid flow pattern also implies the presence of a subaerial exposure along which the meteoric water percolates. In support of this interpretation, Christopher [75] considered tripolitization to be a weathering phenomenon on siliceous rocks attributed to a low $\mathrm{pH}$ subaerial environment, implying an unconformity [76]. Moreover, according to Swanson [77], weathered chert is a definite indication of an unconformity. The tripolite facies in southwest Missouri are indeed characterized by sequence-bounding erosional contact to the top (which can be correlated to a global major eustatic lowstand) and unconformably overlain by the Bentonville Formation [25,37]. The unconformity at the top of the Reeds Spring Formation observed to the west of Mississippian outcrop belt in the tristate area does not extend to the east or further west in the subsurface and thus no tripolite is observed [31]. Due to tertiary erosion, the unconformable contact between Bentonville and Reeds Spring Formations was not observed in the investigated roadcut. Further north along U.S. Hwy 71, however, this unconformable contact can be observed [31]. In addition, clasts of tripolite are observed at the base of the Burlington Formation (formerly referred to as Burlington-Keokuk Formation in the literature), indicating the formation of tripolite before Tertiary [25].

\section{Conclusions}

This work utilized ground-based hyperspectral imaging as a means for detecting and discriminating lithological units in the Reeds Spring Formation in southwestern Missouri. The results demonstrated that horizontal and vertical distribution of the lithological units and mineralogical variations in inaccessible, near-vertical outcrops can be mapped by ground-based hyperspectral imaging rapidly and with high resolution and accuracy. In addition, this work demonstrated that an integrated approach bringing multi-scale, multi-sensor spectral information can provide a more comprehensive way of geological outcrop evaluation. Multi-scale spectral analysis results provided new insight for the formation of the tripolite in the investigated outcrop, complementing previously reported observations on the tripolite exposures in tristate area. We concluded that leaching of carbonates from the rocks and subsequent tripolitization is a result of subaerial exposure caused by meteoric water flowing from the unconformity surface down the vertical succession.

The ground-based hyperspectral image analysis focuses on the outcrop scale and thus, for the evaluation of the diagenetic and geological processes in a greater detail and at a broader scale, a wider analysis including several exposures (where available) should be performed. Apart from the spectral information, the geometry of the lithological units and other geological features are relevant to stratigraphic modeling and reservoir analogues. However, the cylindrical geometry of the ground-based hyperspectral images causes geometric distortions, which remain an important issue to 
be resolved. The rapidly emerging field of ground-based hyperspectral imaging would benefit from further research on correction of such distortions, particularly in the absence of terrestrial LiDAR data.

Acknowledgments: We would like to thank Repsol USA for funding and allowing us to publish the results. We are thankful to the members of GeoRS Lab: Kıvanç Biber, Lei Sun, Casey Snyder, Diana Krupnik, and Virginia Alonso de Linaje for their help during the field work The National Science Foundation is acknowledged for funding the hyperspectral imaging system (Award number 1256202).

Author Contributions: Data collection, processing, and analyses were conducted by Ünal Okyay. He wrote the draft manuscript and prepared the original artwork. Shuhab D. Khan supervised the study at all stages and had an active role in planning the study, data interpretation, and writing and editing the manuscript. M. R. Lakshmikantha and Sergio Sarmiento provided insight for planning of the project and site selection, and commented on the implications of the study. All authors participated in editing the manuscript.

Conflicts of Interest: The authors declare no conflict of interest.

\section{References}

1. Gigli, G.; Casagli, N. Semi-automatic extraction of rock mass structural data from high resolution LIDAR point clouds. Int. J. Rock Mech. Min. Sci. 2011, 48, 187-198. [CrossRef]

2. Matano, F.; Iuliano, S.; Somma, R.; Marino, E.; del Vecchio, U.; Esposito, G.; Mollisso, F.; Scepi, G.; Grimaldi, G.M.; Pignalosa, A. Geostructure of Coroglio tuff cliff, Naples (Italy) derived from terrestrial laser scanner data. J. Maps 2016. [CrossRef]

3. Xu, X.; Aiken, C.L.V.; Bhattacharya, J.P.; Corbeanu, R.M.; Nielsen, K.C.; McMechan, G.A.; Abdelsalam, M.G. Creating virtual 3-D outcrop. Lead Edge 2000, 19, 197-202. [CrossRef]

4. Bellian, J.A. Digital outcrop models: Applications of terrestrial scanning lidar technology in stratigraphic modeling. J. Sediment. Res. 2005, 75, 166-176. [CrossRef]

5. Buckley, S.J.; Schwarz, E.; Terlaky, V.; Howell, J.A.; Arnott, R.W. Combining aerial photogrammetry and terrestrial lidar for reservoir analog modeling. Photogramm. Eng. Remote Sens. 2010, 76, 953-963. [CrossRef]

6. Enge, H.D.; Buckley, S.J.; Rotevatn, A.; Howell, J.A. From outcrop to reservoir simulation model: Workflow and procedures. Geosphere 2007, 3, 469-490. [CrossRef]

7. Humair, F.; Abellan, A.; Carrea, D.; Matasci, B.; Epard, J.L.; Jaboyedoff, M. Geological layers detection and characterisation using high resolution 3D point clouds: Example of a box-fold in the Swiss Jura Mountains. Eur. J. Remote Sens. 2015, 48, 541-568. [CrossRef]

8. Bowen, B.B.; Martini, B.A.; Chan, M.A.; Parry, W.T. Reflectance spectroscopic mapping of diagenetic heterogeneities and fluid-flow pathways in the Jurassic Navajo Sandstone. Am. Assoc. Pet. Geol. Bull. 2007, 91, 173-190. [CrossRef]

9. Bell, J.H.; Bowen, B.B.; Martini, B.A. Imaging spectroscopy of jarosite cement in the Jurassic Navajo Sandstone. Remote Sens. Environ. 2010, 114, 2259-2270. [CrossRef]

10. Asadzadeh, S.; de Souza, F.C.R. A review on spectral processing methods for geological remote sensing. Int. J. Appl. Earth Obs. Geoinf. 2016, 47, 69-90. [CrossRef]

11. Hunt, G.R. Spectral signatures of particulate minerals in the vivible and near infrared. Geophysics 1977, 42, 501-513. [CrossRef]

12. Clark, R.N.; King, T.V.V.; Klejwa, M.; Swayze, G.A.; Vergo, N. High spectral resolution reflectance spectroscopy of minerals. J. Geophys. Res. 1990, 95, 12612-12680. [CrossRef]

13. Bellian, J.A.; Beck, R.; Kerans, C. Analysis of hyperspectral and lidar data: Remote optical mineralogy and fracture identification. Geosphere 2007, 3, 491-500. [CrossRef]

14. Huntington, J.F.; Mauger, A.J.; Skirrow, R.G.; Bastrakov, E.N.; Connor, P.; Mason, P.; Keeling, J.L.; Coward, D.A.; Berman, M.; Phillips, R.; et al. Automated mineralogical core logging at the Emmie Bluff iron oxide-copper-gold prospect. MESA J. 2006, 41, 38-44.

15. Mauger, A.J. Mapping regional alteration patterns using hyperspectral drillcore scanner. ASEG Ext. Abstr. 2007. [CrossRef]

16. Kruse, F.A.; Bedell, R.L.; Taranik, J.V.; Peppin, W.A.; Weatherbee, O.; Calvin, W.M. Mapping alteration minerals at prospect, outcrop and drill core scales using imaging spectrometry. Int. J. Remote Sens. 2012, 33, 1780-1798. [CrossRef] [PubMed] 
17. Kurz, T.H.; Dewit, J.; Buckley, S.J.; Thurmond, J.B.; Hunt, D.W.; Swennen, R. Hyperspectral image analysis of different carbonate lithologies (limestone, karst and hydrothermal dolomites): The Pozalagua Quarry case study (Cantabria, North-west Spain). Sedimentology 2012, 59, 623-645. [CrossRef]

18. Murphy, R.J.; Schneider, S.; Monteiro, S.T. Mapping layers of clay in a vertical geological surface using hyperspectral imagery: Variability in parameters of SWIR absorption features under different conditions of illumination. Remote Sens. 2014, 6, 9104-9129. [CrossRef]

19. Okyay, U.; Khan, S.D. Remote detection of fluid-related diagenetic mineralogical variations in the Wingate Sandstone at different spatial and spectral resolutions. Int. J. Appl. Earth Obs. Geoinf. 2016, 44, 70-87. [CrossRef]

20. Snyder, C.J.; Khan, S.D.; Bhattacharya, J.P.; Glennie, C.; Seepersad, D. Thin-bedded reservoir analogs in an ancient delta using terrestrial laser scanner and high-resolution ground-based hyperspectral cameras. Sediment. Geol. 2016, 342, 154-164. [CrossRef]

21. Krupnik, D.; Khan, S.; Okyay, U.; Hartzell, P.; Zhou, H.-W. Study of Upper Albian rudist buildups in the Edwards Formation using ground-based hyperspectral imaging and terrestrial laser scanning. Sediment. Geol. 2016, 345, 154-167. [CrossRef]

22. Sun, L.; Khan, S. Ground-based hyperspectral remote sensing of hydrocarbon-induced rock alterations at cement, Oklahoma. Mar. Pet. Geol. 2016, 77, 1243-1253. [CrossRef]

23. Zaini, N.; van der Meer, F.D.; van der Werff, H.M.A. Determination of carbonate rock chemistry using laboratory-based hyperspectral imagery. Remote Sens. 2014, 6, 4149-4172. [CrossRef]

24. Greenberger, R.N.; Mustard, J.F.; Cloutis, E.A.; Mann, P.; Wilson, J.H.; Flemming, R.L.; Robertson, K.M.; Salvatore, M.R.; Edwards, C.S. Hydrothermal alteration and diagenesis of terrestrial lacustrine pillow basalts: Coordination of hyperspectral imaging with laboratory measurements. Geochim. Cosmochim. Acta 2015, 171, 174-200. [CrossRef]

25. Mazzullo, S.J.J.; Boardman, D.R.; Wilhite, B.W.; Godwin, C.J.; Morris, B.T. Revisions of outcrop lithostratigraphic nomenclature in the Lower to Middle Mississippian Subsystem (Kinderhookian to Basal Meramecian series) along the shelf-edge in southwest Missouri, northwest Arkansas, and northeast Oklahoma. Shale Shak 2013, 63, 414-454.

26. Gutschick, R.; Sandberg, C. Mississippian continental margins on the conterminous United States. SEPM Spec. Publ. 1983, 33, 79-96.

27. Montgomery, S.L.; Mullarkey, J.C.; Longman, M.W.; Colleary, W.M.; Rogers, J.P. Mississippian "chat" reservoirs, South Kansas: Low-resistivity pay in a complex chert reservoir. Am. Assoc. Pet. Geol. Bull. 1998, 82, 187-205. [CrossRef]

28. Watney, W.L.; Guy, W.J.; Byrnes, A.P. Characterization of the Mississippian chat in south-central Kansas. Am. Assoc. Pet. Geol. Bull. 2001, 85, 85-113.

29. Elebiju, O.O.; Matson, S.; Keller, R.G.; Marfurt, K.J. Integrated geophysical studies of the basement structures, the Mississippi chert, and the Arbuckle Group of Osage County region, Oklahoma. Am. Assoc. Pet. Geol. Bull. 2011, 95, 371-393. [CrossRef]

30. Mazzullo, S.J.; Wilhite, B.W.; Boardman, D.R.; Morris, B.T.; Godwin, C.J. Stratigraphic architecture and petroleum reservoirs in Lower to Middle Mississippian strata (Kinderhookian to basal Meramecian) in subsurface Central to southern Kansas and northern Oklahoma. Shale Shak 2016, 67, 20-49.

31. Mazzullo, S.J.; Wilhite, B.W.; Boardman, D.R. Lithostratigraphic architecture of the Mississippian Reeds Springs Formation (Middle Osagean) in southwest Missouri, northwest Arkansas, and northeast Oklahoma: Outcrop analog of subsurface petroleum reservoirs. Shale Shak 2011, 61, 254-269.

32. Heckel, P.H. Carboniferous Period. In A Concise Geologic Time Scale; Ogg, J.G., Ogg, G., Gradstein, F.M., Eds.; Cambridge University Press: Cambridge, UK, 2008; pp. 73-83.

33. Richards, B.C. Current status of the international carboniferous time scale. In Carboniferous-Permian Transition. New Mexico Museum of Natural History and Science Bulletin 60; Lucas, S.G., DiMichele, W.A., Barrick, J.E., Schneider, J.W., Spielmann, J.A., Eds.; New Mexico Museum of Natural History: Albuquerque, NM, USA, 2013; pp. 348-353.

34. Lane, H.R.; De Keyser, T.L. Paleogeography of the Late Early Mississippian (Tournaisian 3) in the central and southwestern United States. In Paleozoic Paleogeography of the West-Central United States; Fouch, T.D., Magathan, E.R., Eds.; The Rocky Mountain Section SEPM: Denver, CO, USA, 1980; pp. 149-162. 
35. Manger, W.L.; Shelby, P.R. Natural-gas production from the Boone Formation (Lower Mississippian), northwestern Arkansas. In Proceedings of the Platform Carbonates in the Southern Midcontinent, 1996 Symposium, Oklahoma City, OK, USA, 26-27 March 1996.

36. Thompson, T.L. Paleozoic Succession in Missouri, Part 4 Mississippian System; Missouri Department of Natural Resources: Jefferson City, MS, USA, 1986.

37. Mazzullo, S.J. My favorite outcrop-Mississippian tripolite. Shale Shak 2015, 66, 147-149.

38. Color, M. Geological Rock-Color Chart; X-rite Munsell Color: Grand Rapids, MI, USA, 2009.

39. Minor, P.M. Analysis of tripolitic chert in the Boone Formation (Lower Mississippian, Osagean), northwest Arkansas and southwestern Missouri. Master's Thesis, University of Arkansas, Fayetteville, AR, USA, 2013.

40. Mazzullo, S.J.; Wilhite, B.W. Chert, tripolite, spiculite, chat-what's in a name? Kansas Geol. Soc. Bull. 2010, 85, 21-25.

41. Keller, W.D. Textures of tripoli illustrated by scanning electron micrographs. Econ. Geol. 1978, 73, 442-446. [CrossRef]

42. Satterwhite, M.B.; Allen, C.S. A novel, low cost approach for large gray-toned fabric panels for calibrating remotely sensed VIS/NIR/SWIR data. Proc. SPIE 2003, 5093, 163-171. [CrossRef]

43. Rochford, P.A.; Acharya, P.K.; Adler-Golden, S.M.; Berk, A.; Bernstein, L.S.; Matthew, M.W.; Richtsmeier, S.C.; Gulick, S.; Slusser, J. Validation and refinement of hyperspectral/multispectral atmospheric compensation using shadowband radiometers. IEEE Trans. Geosci. Remote Sens. 2005, 43, 2898-2906. [CrossRef]

44. Kurz, T.H.; Buckley, S.J.; Howell, J.A. Close-range hyperspectral imaging for geological field studies: Workflow and methods. Int. J. Remote Sens. 2013, 34, 1798-1822. [CrossRef]

45. Nieke, J.; Schläpfer, D.; Dell’Endice, F.; Brazile, J.; Itten, K.I. Uniformity of imaging spectrometry data products. IEEE Trans. Geosci. Remote Sens. 2008, 46, 3326-3336. [CrossRef]

46. Watson, K. Processing remote sensing images using the 2-D FFT-noise reduction and other applications. Geophysics 1993, 58, 835-852. [CrossRef]

47. Kennedy, R.E.; Cohen, W.B.; Takao, G. Empirical methods to compensate for a view-angle-dependent brightness gradient in AVIRIS imagery. Remote Sens. Environ. 1997, 62, 277-291. [CrossRef]

48. Schiefer, S.; Hostert, P.; Damm, A. Correcting brightness gradients in hyperspectral data from urban areas. Remote Sens. Environ. 2006, 101, 25-37. [CrossRef]

49. Smith, G.M.; Milton, E.J. The use of the empirical line method to calibrate remotely sensed data to reflectance. Int. J. Remote Sens. 1999, 20, 2653-2662. [CrossRef]

50. Savitzky, A.; Golay, M.J.E. Smoothing and differentiation of data by simplified least squares procedures. Anal. Chem. 1964, 36, 1627-1639. [CrossRef]

51. Ruffin, C.; King, R. The analysis of hyperspectral data using Savitzky-Golay filtering-Theoretical basis (Part 1). In Proceedings of the IEEE 1999 International Geoscience and Remote Sensing Symposium, Hamburg, Germany, 28 June-2 July 1999.

52. Green, A.A.; Berman, M.; Switzer, P.; Craig, M.D. Transformation for ordering multispectral data in terms of image quality with implications for noise removal. IEEE Trans. Geosci. Remote Sens. 1988, 26, 65-74. [CrossRef]

53. Atkinson, P.M.; Sargent, I.M.; Foody, G.M.; Williams, J. Interpreting image-based methods for estimating the signal-to-noise ratio. Int. J. Remote Sens. 2005, 26, 5099-5115. [CrossRef]

54. Van der Meer, F.D.; de Jong, S.M.; Bakker, W.H. Imaging spectrometry: Basic analytical techniques. In Imaging Spectrom: Basic Principles and Prospective Applications; Van Der Meer, F.D., de Jong, S.M., Eds.; Springer: Dordrecht, The Netherlands, 2001; pp. 17-61.

55. Clark, R.N.; Gallagher, A.J.; Swayze, G.A. Material absorption band depth mapping of imaging spectrometer data using a complete band shape least-squares fit with library reference spectra. In Proceedings of the Second Airborne Visible/Infrared Imaging Spectrometer Workshop, Pasadena, CA, USA, 4-5 June 1990; pp. 176-186.

56. Clark, R.N.; Swayze, G.A.; Gallagher, A.J.; Gorelick, N.; Kruse, F.A. Mapping with imaging spectrometer data using the complete band shape least-squares algorithm simultaneously fit to multiple spectral features from multiple materials. In Proceedings of the Third Airborne Visible/Infrared Imaging Spectrometer Workshop, Pasadena, CA, USA, 20-21 May 1991; pp. 2-3.

57. Harsanyi, J.C.; Chang, C.I. Hyperspectral image classification and dimensionality reduction: An orthogonal subspace projection approach. IEEE Trans. Geosci. Remote Sens. 1994, 32, 779-785. [CrossRef] 
58. Boardman, J.W.; Kruse, F.A.; Green, R.O. Mapping target signatures via partial unmixing of AVIRIS data. In Proceedings of the 5th JPL Airborne Earth Science Workshop, Pasadena, CA, USA, 23-26 January 1995; pp. 23-26.

59. Boardman, J.W. Leveraging the high dimensionality of AVIRIS data for improved sub-pixel target unmixing and rejection of false positives: mixture tuned matched filtering. In Proceedings of the 7th JPL Airborne Earth Science Workshop, Pasadena, CA, USA, 12-16 January 1998; pp. 55-56.

60. Debba, P.; Van Ruitenbeek, F.J.A.; Van Der Meer, F.D.; Carranza, E.J.M.; Stein, A. Optimal field sampling for targeting minerals using hyperspectral data. Remote Sens. Environ. 2005, 99, 373-386. [CrossRef]

61. Pan, Z.; Huang, J.; Wang, F. Multi range spectral feature fitting for hyperspectral imagery in extracting oilseed rape planting area. Int. J. Appl. Earth Obs. Geoinf. 2013, 25, 21-29. [CrossRef]

62. van der Meer, F.D. Analysis of spectral absorption features in hyperspectral imagery. Int. J. Appl. Earth Obs. Geoinf. 2004, 5, 55-68. [CrossRef]

63. Tangestani, M.H.; Jaffari, L.; Vincent, R.K.; Sridhar, B.B.M. Spectral characterization and ASTER-based lithological mapping of an ophiolite complex: A case study from Neyriz ophiolite, SW Iran. Remote Sens. Environ. 2011, 115, 2243-2254. [CrossRef]

64. Kruse, F.A.; Boardman, J.W.; Huntington, J.F. Comparison of airborne hyperspectral data and EO-1 Hyperion for mineral mapping. IEEE Trans. Geosci. Remote Sens. 2003, 41, 1388-1400. [CrossRef]

65. Nidamanuri, R.R.; Zbell, B. Use of field reflectance data for crop mapping using airborne hyperspectral image. ISPRS J. Photogramm. Remote Sens. 2011, 66, 683-691. [CrossRef]

66. Clark, R.N. Spectroscopy of rocks and minerals, and principles of spectroscopy. Man. Remote Sens. 1999, 3, 3-58. [CrossRef]

67. Gaffey, S.J. Reflectance spectroscopy in the visible and near-infrared (0.35-2.55 $\mu \mathrm{m})$ : Applications in carbonate petrology. Geology 1985, 13, 270. [CrossRef]

68. Sherman, D.M.; Waite, T.D. Electronic spectra of Fe3+ oxides and oxide hydroxides in the near IR to near UV. Am. Mineral. 1985, 70, 1262-1269.

69. Chabrillat, S.; Goetz, A.F.H.; Olsen, H.W.; Krosley, L. Field and imaging spectrometry for identification and mapping of expansive soils. In Basic Principles and Prospective Applications: Imaging Spectrometry; van der Meer, F.D., de Jong, S.M., Eds.; Springer: Dordrecht, The Netherlands, 2001; pp. 87-109.

70. Gupta, R.P. Spectra of minerals and rocks. In Remote Sensing Geology, 2nd ed.; Springer: Berlin/Heidelberg, Germany, 2003; pp. 33-52.

71. Gaffey, S.J. Spectral reflectance of carbonate minerals in the visible and near infrared (0.35-2.55 microns): Calcite, aragonite, and dolomite. Am. Mineral. 1986, 71, 151-162.

72. Bishop, J.L.; Lane, M.D.; Dyar, M.D.; Brown, A.J. Reflectance and emission spectroscopy study of four groups of phyllosilicates: Smectites, kaolinite-serpentines, chlorites and micas. Clay Miner. 2008, 43, 35-54. [CrossRef]

73. Harris, J.R.; Rogge, D.; Hitchcock, R.; Ijewliw, O.; Wright, D. Mapping lithology in Canada's Arctic: Application of hyperspectral data using the minimum noise fraction transformation and matched filtering. Can. J. Earth Sci. 2005, 42, 2173-2193. [CrossRef]

74. Manger, W.L. Tripolitic chert development in the Mississippian lime: New insights from SEM. Presented at Mississippian Lime Play Forum, Oklahoma City, OK, USA, 20 February 2014.

75. Christopher, J.E. The Lower Cretaceous Mannville Group, northern Williston Basin region, Canada. In The Mesozoic of Middle North America: A Selection of Papers from the Symposium on the Mesozoic of Middle North America, Calgary, Alberta, Canada-Memoir 9, 1984; Canadian Society of Petroleum Geologists: Calgary, AB, Canada, 1984; Volume 9, pp. 109-126.

76. Christopher, J.E. The Lower Cretaceous Mannville group of Saskatchewan-A tectonic overview. Saskatchewan Geol. Soc. Spec. Publ. 1980, 5, 3-32.

77. Swanson, R.G. Sample Examination Manual; American Association of Petroleum Geologists: Tulsa, Ok, USA, 1981.

(C) 2016 by the authors; licensee MDPI, Basel, Switzerland. This article is an open access article distributed under the terms and conditions of the Creative Commons Attribution (CC-BY) license (http://creativecommons.org/licenses/by/4.0/). 